\title{
I. Krise und Kritik: Zur Welle des antidemokratischen Denkens in der Zwischenkriegszeit
}

\section{Konjunktur der Krisen}

Die Entwicklungsphasen von Konservativer Revolution und Nonkonformismus verliefen nicht zeitgleich. Die Welle der Agitation gegen die Weimarer Republik setzte unmittelbar nach dem Weltkrieg ein und erreichte Anfang der dreißiger Jahre ihren Höhepunkt. Die Konjunkturzyklen der Kritik entsprechen weitgehend den Krisenjahren der Republik: 1919 bis 1923 und 1929 bis 19321. Der Sieg der Nationalsozialisten bedeutete für die Konservative Revolution Erfolg und Scheitern zugleich: Erfolg im Kampf gegen das verhaßte Weimarer System, Scheitern im Ringen um die Macht.

Im entsprechenden Zeitraum gab es in Frankreich keine Krise von vergleichbaren Ausmaßen. Die Situation in beiden Ländern war von den denkbar größten Gegensätzen geprägt. Während im Nachkriegsjahrzehnt in Deutschland Unsicherheit und Umbruch herrschten, erlebte Frankreich eine Phase der Stabilität und der relativen Prosperität. Nicht nur die Regierungsform überdauerte den Krieg, auch die Politikergeneration, die in der Dreyfus-Affäre an die Macht gekommen war, garantierte eine Kontinuität der politischen Leitlinien ${ }^{2}$. Die zwanziger Jahre waren geprägt durch die konservative Stabilisierungspolitik des Nationalen Blocks und der Nationalen Union. Nur während der Regierung des Linkskartells von 1924 bis 1926 erhielten die rechtsextremistischen Bewegungen einen deutlichen Zulauf. In diese Phase fällt auch die Gründung der Legion (1924), der Jeunesses Patriotes (1924) und des Faisceau (1925). Diese „erste Welle des Faschismus" (Soucy) verebbte jedoch rasch wieder, nachdem die Rechte an die Macht zurückgekehrt war. Auch auf dem Höhepunkt ihres Einflusses überstieg die Zahl ihrer Anhänger kaum $150000^{3}$. Im Nachkriegsjahrzehnt unterschieden sich somit die Rahmenbedingungen und das Ausmaß der Kritik fundamental. Erst mit den dreißiger Jahren begann in Frankreich eine Krise, die an Dauer und Radikalität mit derjenigen der Weimarer Republik vergleichbar war.

Durch seine engen Verflechtungen mit den internationalen Kapitalmärkten war Frankreich ebenso wie die übrigen europäischen Staaten vom Börsenkrach an der Wall Street betroffen. Allerdings wurden die Auswirkungen erst mit einer Verzögerung von zwei Jahren spürbar. Die Abwertung des Pfund im September 1931 traf den französischen Außenhandel empfindlich. Vor allem aber führte die Krise in eine dauerhafte Depression. Erst 1939 hat das Bruttoinlandsprodukt wieder den Stand von 1928 erreicht ${ }^{4}$. Weniger ihr Ausmaß als vielmehr ihre Dauer gefährdete die soziale Stabilität, beengte

\footnotetext{
${ }^{1}$ Mohler, Konservative Revolution, Bd. 1, S. 40; Peukert, Weimarer Republik, S. 61ff., $191 \mathrm{ff} ., 243 \mathrm{ff} . ;$ Kolb, Weimarer Republik, S. 35ff., 54ff., 107ff.; Winkler, Weimar, S. $109 \mathrm{ff}$., 244ff., $335 \mathrm{ff}$.

2 Vgl. Brunschwig, Die historischen Generationen, S. 373-385.

${ }^{3}$ Soucy, First Wave, S. XIf. und 217; vgl. allgemein zu den zwanziger Jahren Becker/Berstein, Victoire et frustrations.

${ }^{4}$ Sauvy, Histoire économique, Bd. 2, S. 528.
} 
den politischen Handlungsspielraum und stürzte die Republik in eine tiefe Legitimationskrise. Die Depression verschärfte die bereits bestehende soziale Ungleichheit, sie traf vor allem die Landbevölkerung, Arbeiter und Mittelschichten. Die Baubranche, die Metall-, Elektro- und die Textilindustrie erlitten die stärksten Rückschläge. Von den zahlreichen Konkursen der kleineren Unternehmer profitierten einige wenige Großunternehmen, die auf diese Weise ihre Marktposition ausbauen konnten. Noch später als die wirtschaftlichen wurden die sozialen Folgen der Krise spürbar. Von der Arbeitslosigkeit waren zunächst vor allem Gastarbeiter und Frauen betroffen. Im Vergleich zu Deutschland war die Arbeitslosigkeit zwar gering, doch stieg sie bis 1936 stetig an und sank danach nur langsam. Im Jahr 1935 gab es rund eine halbe Million Arbeitslose, die öffentliche Unterstützung bezogen, ein Drittel bis die Hälfte aller Arbeitnehmer leistete Kurzarbeit 5 .

Auch außenpolitisch markierten die beginnenden dreißiger Jahre den Anfang eines kontinuierlichen Abstiegs: Die Regelungen der Reparationszahlungen und der Abrüstung machten den Einflußverlust Frankreichs und seine Abhängigkeit von den amerikanischen Finanzmärkten deutlich. Die offensive Revisionspolitik der Nachfolger Stresemanns bedeutete das Ende der Locarno-Ära und der deutsch-französischen Verständigungspolitik. Die Versuche, Deutschland in das System der kollektiven Sicherheit einzubinden, waren zum Scheitern verurteilt. Frankreich sah sich im Laufe der dreißiger Jahre immer deutlicher von der ehemaligen kontinentalen Hegemonialstellung zu einer zweitrangigen Macht zurückgestuft, während der Nachbar östlich des Rheins seine strukturelle Überlegenheit ausbauen konnte ${ }^{6}$.

Wirtschaftliche Depression und soziale Desintegration erreichten in der zweiten Hälfte des Jahrzehnts ihren Höhepunkt und verschafften den extremistischen Kräften erheblichen Auftrieb. Zur Erklärung dieser Entwicklung hat Stanley Hoffmann ein Strukturmodell entwickelt, das den Zusammenhang zwischen wirtschaftlicher Modernisierung und politischer Stabilität beschreibt. Mit den Begriffen der „blockierten Gesellschaft" und der "republikanischen Synthese" bezeichnet Hoffmann eine Phase der politischen Stabilität, die von der Gründung der Republik bis in die Mitte der dreißiger Jahre hineinreichte, die jedoch um dem Preis einer geringen sozialen Mobilität und eines niedrigen industriellen Wachstums erkauft wurde. Unter der „republikanischen Synthese" versteht Hoffmann den Konsens zwischen den Mittelschichten in Stadt und Land und einem Teil des Großbürgertums über die sozialen Prinzipien der Republik. Diese Synthese basierte auf dem Kräftegleichgewicht vorindustrieller und industrieller Gesellschaftsschichten, die sich durch ihre gegensätzlichen Interessenlagen gegenseitig blokkierten. Das prekäre Gleichgewicht garantierte ein halbes Jahrhundert lang Stabilität, ein langsames Wachstum und soziale Sicherheit für die beteiligten Schichten, verhinderte aber einen Ausbau des Sozialsystems und schloß die Industriearbeiter aus. Dem sozialen Konsens fehlte die politische Entsprechung. Der Staat sollte als Vermittlungsinstanz auftreten, aber sich darüber hinaus keineswegs in wirtschaftspolitische Fragen einmischen. In dem Moment, wo die sozialen Grundlagen der Synthese ins Wanken gerieten, weil

\footnotetext{
${ }^{5}$ Bouvier/Armengand/Barral u. a., Temps, S. 655ff.; Sauvy, Histoire économique, Bd. 2, S. 15ff., Tabelle S. 554; vgl. Borne/Dubief, Crise, S. $20 \mathrm{ff}$.

6 Vgl. Duroselle, Décadence; Schuker, End.
} 
der Verteilungsspielraum enger wurde, mußte die prekäre Balance zerbrechen und die extremistischen Kräfte freisetzen 7 . Dieses Modell ist von der neueren Forschung häufig korrigiert und in Einzelaspekten modifiziert worden. Vor allem die normativen Implikationen von „Modernisierung“ und „Mobilität“ wurden zu Recht kritisiert. Zudem hat Hoffmann das Ausmaß der Blockade überschätzt. Jedoch bleibt der heuristische Wert des Modells in seinen zentralen Aussagen erhalten ${ }^{8}$.

Genau dieser soziale Wandel war in den dreißiger Jahren unvermeidlich geworden. Infolge der andauernden Depression gerieten die Parteien immer mehr in den Sog wirtschaftlicher Interessengruppen und verloren ihren Handlungsspielraum. Eine Alternative zur „republikanischen Synthese“ formierte sich im Bündnis der Kommunisten mit den Sozialisten und bürgerlichen Linksparteien, aus dem die Volksfront hervorging. Ihr Siegeszug im Zeichen des „Antifaschismus“ zerstörte den Konsens zwischen Mittelschichten und Großbürgertum und verschaffte den extremistischen Kräften starken $\mathrm{Zu}$ lauf 9 . Die Situation erhielt dadurch zusätzliche Brisanz, daß die außenpolitisch-ideologische Konfrontation zwischen Nationalsozialismus, Faschismus und Kommunismus immer mehr die innerfranzösischen Auseinandersetzungen überlagerte ${ }^{10}$. Während der Regierung der Volksfront erreichte die Polarisierung ihren Höhepunkt, die ideologischen Bürgerkriegsparteien bekämpften sich unerbittlich und schufen ein Klima der Angst und der Gewalt, das sich in Streiks, Straßenkämpfen und Terror entlud. Diese Situation weist - weniger in ihren konkreten Erscheinungen als vielmehr in den Dimensionen des Konfliktes - deutliche Parallelen zur Weimarer Republik auf. Die aufbrechenden sozialen Konflikte beschleunigten die Desintegration des parlamentarischen Systems und gaben seinen Kritikern Auftrieb. Auch der Zusammenbruch der Dritten Republik nach der militärischen Niederlage zeigte noch einmal, wie stark der Glaube an die Erneuerungskräfte der parlamentarischen Demokratie erschüttert war.

Erst in den dreißiger Jahren erhielten die extremistischen Bewegungen einen deutlichen Zulauf, die „zweite Welle“ des Faschismus in Frankreich war erheblich größer und länger als die erste. Neben den alten Ligen formierten sich neue Kräfte: der zahlenmäßig unbedeutende, aber militante Francisme (1933) von Marcel Bucard; die vom Parfumfabrikanten François Coty gegründete Solidarité française (1933), die sich nach dem Tod ihres Mäzens 1934 zum radikal antisemitischen Kampfbund entwickelte. Die bedeutendste Bewegung der dreißiger Jahre waren jedoch die Feuerkreuzler (Croix de Feu), ein Frontkämpferverband, der sich unter der Führung des Colonel François de la Rocque für jüngere Sympathisanten öffnete und einen enormen Zulauf verzeichnete: seine Anhängerzahl stieg von rund 10000 am Anfang des Jahrzehnts auf 600000 im Jahr 1936. Nach der Umwandlung seiner Bewegung in den Parti Social Français (PSF) stand La Rocque an der Spitze der größten Partei Frankreichs, die zwischen 700000 und 1,2 Millionen Mitglieder hatte. Damit erreichte der PSF den Stand der NSDAP-Anhänger zum Zeitpunkt der Machtergreifung (850 000), im Verhältnis zur Bevölkerung übertraf er sogar den Anteil der Partei Hitlers (1,8 zu 1,5 Prozent) ${ }^{11}$. Das Lager der extremen Rechten

\footnotetext{
${ }^{7}$ Hoffmann, Paradoxes, S. $3 \mathrm{ff}$.

${ }^{8}$ Vgl. Haupt, Sozialgeschichte, S. 8f., 266ff.; Bouvier, Einleitung, in: Capitalisme français, S. 11-32.

${ }^{9}$ Hoffmann, Paradoxes, S. $26 \mathrm{ff}$.

10 Vgl. Wirsching, Kollaborationsideologie, S. 31-60.

$"$ Soucy, Second Wave, S. 104ff.; zur NSDAP vgl. die Übersicht bei Frei, Führerstaat, S. 257.
} 
erhielt Zulauf von den Dissidenten der Linken: Der kommunistische Bürgermeister von Saint-Denis, Jacques Doriot, der Sozialist Marcel Déat und der Radikalsozialist Gaston Bergery überwarfen sich mit ihren Parteien und gründeten eigene, autoritäre Bewegungen, die in den Bannkreis des französischen Faschismus gerieten ${ }^{12}$.

Die Nonkonformisten hatten bereits Ende der zwanziger Jahre begonnen, ein Netz persönlicher Verbindungen zu flechten. Daraus entstanden in den dreißiger Jahren Intellektuellenzirkel, die in selbstgegründeten Zeitschriften ihren Protest artikulierten. Mit ihrer radikalen Kritik an den Grundlagen der industriellen Massengesellschaft und der parlamentarischen Demokratie nahmen sie die Krise bereits wahr, als sich ihre ersten Symptome in der internationalen Politik und den Auswirkungen der Weltwirtschaftskrise abzuzeichnen begannen. Einen ersten Höhepunkt erreichten diese Aktivitäten im Dezember 1932, als die jungen Intellektuellen mit dem Cahier de Revendications ihren gemeinsamen Auftritt in der Nouvelle Revue Française hatten. Nach außen hin präsentierten sie ihre Geschlossenheit als eine „dritte Front“, die jenseits der traditionellen politischen Lager nach einer neuen Orientierung in der Krise suchte ${ }^{13}$.

Über diese frühe Phase des Protestes herrscht in der Forschung weitgehend Einigkeit. In der weiteren Bewertung des Phänomens findet der Konsens jedoch ein jähes Ende. Hier stehen sich im wesentlichen zwei Ansichten unversöhnlich gegenüber. Die eine wird von der Schule der französischen Historiker aus dem Umkreis des Institut d'Études Politiques vertreten, die der Interpretation Jean Touchards folgen. Er setzt die entscheidende Zäsur bereits 193414. Nach dem Aufmarsch der Ligen vor dem Sitz der Nationalversammlung im Februar und den folgenden Debatten um die Existenz eines französischen Faschismus zerbrach demzufolge die Gemeinschaft. Die Anhänger dieser These gehen davon aus, daß die Nonkonformisten in die traditionellen Bahnen des politischen Engagements zurückgekehrt sind ${ }^{15}$. Diese Sichtweise vertreten auch Gilbert Merlio und Hans Manfred Bock in ihren Beiträgen in dem Band Ni gauche, ni droite. Bei ihrem Vergleich von Nonkonformismus und Konservativer Revolution können sie daher von einem annähernd zeitgleichen Kulminationspunkt Anfang der dreißiger Jahre ausgehen ${ }^{16}$.

Dieser Auffassung steht die These von Zeev Sternhell gegenüber, wonach die Debatten der Nonkonformisten eine Kontinuität über den Februar 1934 hinaus bis zum Zusammenbruch der Republik auszeichnet. Demnach sind sie durch die Faschismus-

12 Burrin, Dérive; Brunet, Doriot; sowohl methodisch als auch von der Breite des untersuchten Materials dahinter zurückstehend: Schwarzer, Vom Sozialisten zum Kollaborateur; zur Kritik an dem Faschismusbegriff vgl. Müller, Faschisten von Links?, S. 170-191.

${ }_{13}$ Trebitsch, Le front commun, S. 209-227.

14 Touchard, L'esprit, S. $107 f$.

15 Ebenda, S. 108ff.; Loubet del Bayle, Non-conformistes, S. 177. Der Standpunkt von Trebitsch unterscheidet sich allenfalls in Nuancen von demjenigen Loubet del Bayles, vgl. Trebitsch, Le front commun, S. 221; vgl. auch Roy, Alexandre Marc. Bruno Ackermann berücksichtigt in seiner Rougemont-Biographie diese Zäsur nicht. Vielmehr zielt sie bereits in ihrer Fragestellung primär auf die "cohérence intellectuelle" und „unité personnelle“ seines Lebensweges. Der tagespolitische Kontext ist durchaus präsent und teilweise sehr detailliert rekonstruiert. Doch steht die Untersuchung unter der Prämisse, daß Rougemonts Engagement in den dreißiger Jahren eine Fortsetzung in direkter Linie durch seinen Einsatz für den europäischen Föderalismus nach dem Zweiten Weltkrieg gefunden habe, Ackermann, Rougemont, Zitate Bd. 1, S. 38, vgl. Bd. 2, S. 835.

${ }^{16}$ Bock, Crise, S. 299-311; Merlio, Préface zu Ni gauche, S. 7-13. 
debatte und den Sieg der Volksfront 1936 keineswegs isoliert worden, sondern haben im Gegenteil erst ein politisches Klima vorgefunden, das ihren Thesen die geeigneten Rezeptionsbedingungen verschaffte ${ }^{17}$. Sternhells umfassender Faschismusbegriff ist nicht dazu geeignet, den genauen Standort der Nonkonformisten innerhalb der ideologischen Fronten zu bestimmen. Jedoch betont er zu Recht die Verwandtschaft der Themen und der Argumentationsmuster mit den Positionen, die der Faisceau (1925-1928) von Georges Valois und die linken Revisionisten, Doriot, Déat und Bergery, in den dreißiger Jahren vertreten haben ${ }^{18}$. Wenn seine Analysen aufgrund dieses denkbar weiten Ansatzes und seiner rein ideengeschichtlichen Orientierung zu Recht scharf angegriffen wurden, so hat sich bisher keiner seiner Kritiker die Mühe gemacht, die Substanz dieser These für die Jeune Droite und den Ordre Nouveau nach $1934 \mathrm{zu}$ überprüfen ${ }^{19}$. Allerdings hat bereits vor dem Erscheinen von Sternhells Werk der kanadische Historiker John Hellman in seiner Untersuchung über Emmanuel Mounier and the New Catholic Left auf die Ambiguitäten in der Haltung des Esprit-Chefredakteurs hingewiesen und die Pionierstudie von Michel Winock in einigen Aspekten korrigiert. Deutlich stellt er den Einfluß antiliberaler Ideen bei Mounier heraus, die seine zeitweilige Sympathie für den italienischen Faschismus, seine Kontakte zu den belgischen Rexisten und zu nationalsozialistischen Kreisen um Otto Abetz erklären ${ }^{20}$.

Dem Engagement der Intellektuellen der Jeune Droite und des Ordre Nouveau nach 1934 ist - mit Ausnahme von Sternhell - wenig Aufmerksamkeit geschenkt worden. Zur Jeune Droite existieren zwar einige Arbeiten für die Zeit nach 1934, deren Aussagewert jedoch entweder durch eine isolierte Betrachtung ${ }^{21}$ oder durch eine apologetische Perspektive 22 beeinträchtigt wird. Die Untersuchung von Edmond Lipiansky über den Ordre Nouveau verspricht zwar eine Behandlung des Zeitraums bis 1938 (dem Ende der gleichnamigen Zeitschrift), beschränkt sich jedoch entgegen ihrem Anspruch auf die erste Hälfte der dreißiger Jahre ${ }^{23}$. Der Eindruck einer Isolation der nonkonformistischen Intellektuellen insbesondere nach 1934 ergibt sich vor allem aus der fehlenden Einbettung in den ideologischen und politischen Kontext und der ungenügenden Rekonstruktion des Kommunikationsnetzes. Dies kann zum Teil damit entschuldigt werden, daß die Ergebnisse der oben genannten fundierten neueren Untersuchungen über die extremistischen Bewegungen von links und rechts (Soucy, Burrin, Brunet) noch nicht vorlagen und einige Archivmaterialien noch nicht zugänglich waren. Zum anderen aber hat die Fixierung der französischen Schule auf die Phase bis 1934 dazu beigetragen, daß auch verfügbares Material wie das Umfeld der Presse überhaupt nicht genutzt und größere Zusammenhänge nicht ins Blickfeld genommen wurden.

\footnotetext{
17 Sternhell, Ni droite, S. 234ff.

${ }^{18}$ Ebenda, S. 25ff.; vgl. ders., La troisième voie fasciste, S. 17-29.

19 Vgl. Berstein, La France des années trente allergique au Fascisme, S. 83-94; Julliard, Fascisme imaginaire, S. 849-861; Winock, Fascisme, S. 35-44.

${ }^{20}$ Hellman, Mounier; ders., Personnalisme, S. 116-129; vgl. Winock, Esprit; Sternhell, Mounier, S. 1141-1180.

${ }^{21}$ Leroy/Roche, Les Ecrivains, S. 61-72; Leroy, Combat, S. 122-134.

22 Pierre Andreu war ein ehemaliger Anhänger der Jeune Droite; vgl. Andreu, Le Rouge; ders., Revoltés.

${ }^{23}$ Lipiansky, L'Ordre Nouveau, S. 1-103.
} 
Die Begrenzung des Vergleichs auf die Zeit zwischen 1930 und 1933/34 erscheint somit fragwürdig: In dieser Phase erreichte die Konservative Revolution ihren Höhepunkt, während in Frankreich die Krise erst begann. Da die Entwicklung von Konservativer Revolution und Nonkonformismus nicht zeitgleich verlief, ist ein direkter Vergleich der Argumentationsmuster, der politischen Einstellungen usw. unmöglich. Dies ist durchaus erwünscht: Es bewahrt vor der Suche nach vordergründigen Analogien und zwingt dazu, die Phänomene zunächst in ihren jeweiligen nationalen Rahmen einzuordnen, bevor die vergleichende Perspektive eröffnet wird. Anhand von drei Themenkomplexen, Sozialisation, Generationserfahrungen und Intellektuellenkultur, werden im folgenden die Bedingungen für einen Vergleich weiter präzisiert.

\section{Herkunft und Bildungsweg}

Die radikale Kritik an den bürgerlichen Wertvorstellungen kam mitten aus den eigenen Reihen: Die Akteure beiderseits des Rheins stammten aus bürgerlichen Elternhäusern und waren durch eine entsprechende Erziehung und Ausbildung geprägt. Innerhalb der Konservativen Revolution gab es jedoch - wie Stefan Breuer hervorhebt - immer noch beträchtliche soziale Unterschiede. Das Spektrum erstreckte sich von Angehörigen des absteigenden Handwerks ${ }^{24}$ über kaufmännische Angestellte ${ }^{25}$ bis hin zu Vertretern des Bildungsbürgertums meist im höheren Beamtenverhältnis ${ }^{26}$ und Freiberuflern ${ }^{27}$. Wenn dieser Überblick aufgrund der vorliegenden Größenordnungen anfechtbar bleibt, so läßt sich doch ein Schwerpunkt im gehobenen Bürgertum lokalisieren. In Frankreich kann man mit denselben Vorbehalten die Akteure ebenfalls dieser Schicht zurechnen. Allerdings war das soziale Spektrum deutlicher abgegrenzt. Die Väter der Intellektuellen, deren Berufe sich ermitteln ließen (13), stammten fast ausschließlich aus dem mittleren und gehobenen Bürgertum: ein Bankangestellter ${ }^{28}$, ein Pastor $^{29}$, zwei Lehrer mit Agrégation ${ }^{30}$, zwei Ärzte ${ }^{31}$, ein Richter ${ }^{32}$, ein Offizier ${ }^{33}$, zwei Ministerialbeamte ${ }^{34}$, ein Bauunternehmer ${ }^{35}$ und ein Spekulant ${ }^{36}$. Der höhere soziale Status der Akteure verwundert kaum, wenn man sich vergegenwärtigt, daß es überwiegend Absolventen der Pariser

${ }^{24}$ Ernst Niekisch, Wilhelm Stapel; vgl. hier und im folgenden Breuer, Anatomie, S. 27.

${ }^{25}$ Carl Schmitt.

${ }^{26}$ Moeller van den Bruck, Martin Spahn, Edgar Julius Jung, Hans Freyer, Hans Zehrer.

27 Ernst und Friedrich Georg Jünger, Leopold Ziegler.

${ }^{28}$ Robert Aron; vgl. ders., Fragments, S. 247.

29 Denis de Rougemont, vgl. Ackermann, Rougemont, Bd. 1, S. 64.

${ }^{30}$ Claude Chevalley: Archives Nationales (AN) 61 AJ 253; Thierry Maulnier, eigentlich Jacques Talagrand: AN 61 AJ 255.

${ }^{31}$ Pierre Andreu, vgl. ders., Le Rouge, S. 15; Robert Castille: AN F7 13983/14, Bericht vom Mai 1936.

32 Jean Jardin, vgl. Assouline, Eminence grise, S. 20.

33 Robert Brasillach: AN 61 AJ 255.

${ }^{34}$ Jean de Fabrègues, vgl. Auzépy-Chavagnac, Fabrègues, S. 28; Claude Roy, vgl. ders., Moi - je, S. 111 .

${ }^{35}$ Robert Francis, eigentlich Jean Godmé, und Jean-Pierre Maxence, eigentlich Pierre Godmé. Sie waren Brüder; vgl. J.-L. Maxence, L'ombre d'un père, S. 41.

${ }^{36}$ Alexandre Marc, eigentlich Alexandre Marc Lipiansky, vgl. Roy, Marc, S. 92. 
Elitehochschulen waren, die sich im Ordre Nouveau und der Jeune Droite zusammenfanden.

Ein weiteres Merkmal, das Breuer an der Konservativen Revolution beobachtet, trifft auch für die Nonkonformisten zu: Die überwiegende Mehrheit der Protagonisten war in Städten der Provinz aufgewachsen, jedoch entfalteten sie ihre Aktivitäten erst in den Metropolen ${ }^{37}$. In Hamburg bildete sich ein Kreis um die von Wilhelm Stapel herausgegebene Zeitschrift Deutsches Volkstum (1919-1938), in München sammelte sich ein Zirkel um Edgar Julius Jung ${ }^{38}$. Das Zentrum der Konservativen Revolution war jedoch zweifellos die Hauptstadt Berlin. Dort entwickelte sich eine schier unübersehbare Vielfalt von Bewegungen und Zeitschriften, von den Jungdeutschen über die Jungkonservativen bis hin zu den Nationalrevolutionären. Zu letzteren gehörten die Zeitschriften Widerstand von Ernst Niekisch (Dresden 1926-1929/Berlin 1930-1934), Die Nationalbolschewistischen Blätter (1931-1933) von Karl Otto Paetel und Gegner (1931-1933) um Harro Schulze-Boysen. Ernst Jünger gab mit einigen Gesinnungsgenossen Die selbständige Standarte (1926) und Arminius (1926-1927) heraus. Otto Strasser schuf mit der Schwarzen Front eine Sammlungsbewegung für dissidente Nationalsozialisten und Sympathisanten der extremen Rechten ${ }^{39}$. Einen außerordentlichen Erfolg verzeichnete seit dem Beginn der dreißiger Jahre die von Hans Zehrer geleitete Zeitschrift Tat, die 1932 eine Auflage von 30000 Exemplaren erreichte ${ }^{40}$. Zu den einflußreichsten Gruppierungen der Konservativen Revolution gehörte der Juniklub. Er bildete das geistige Zentrum der Jungkonservativen, das sich um Moeller van den Bruck gruppierte. Zu seinen Organen gehörten Das Gewissen (1919-1927), herausgegeben von Eduard Stadtler, und Der Ring, seit 1928 unter der Leitung von Heinrich von Gleichen, und die von Rudolf Pechel herausgegebene Deutsche Rundschau ${ }^{41}$.

In Frankreich läßt sich eine ähnliche Entwicklung beobachten. Drei Viertel (18 von 24) der Anhänger des Ordre Nouveau und der Jeune Droite waren (soweit der Geburtsort bekannt ist) nicht in Paris geboren und aufgewachsen. Die überwiegende Mehrheit hatte dort jedoch studiert und Bekanntschaft geschlossen (20 von 24). Der Nonkonformismus war - bedingt durch den extremen Zentralismus in Frankreich - noch stärker auf die Hauptstadt konzentriert. Hier waren nicht nur die renommierten Universitäten, Privathochschulen und Grandes Ecoles angesiedelt, sondern auch alle bedeutenden Verlagshäuser, die großen Presseagenturen und überregionalen Tageszeitungen ebenso wie die tonangebenden Monatszeitschriften. Diese hohe geographische Konzentration hatte

\footnotetext{
${ }^{37}$ Aus dem engeren Kreis der Konservativen Revolutionäre war nur Hans Zehrer in einer Metropole (Berlin) aufgewachsen; Breuer, Anatomie, S. 27, zur Auswahl des engeren Kreises vgl. ebenda, S. 6.

${ }^{38}$ Mohler, Konservative Revolution, Bd. 1, S. $410 \mathrm{ff}$.

${ }^{39}$ Für die fast unüberschaubare Zahl kleinerer Gruppierungen und Zeitschriften bietet das Werk von Mohler immer noch die beste Orientierungshilfe. Mohler, Konservative Revolution, Bd. 1, S. 293ff., 401ff.; zu den hier als nationalrevolutionär bezeichneten Bewegungen siehe Dupeux, „Nationalbolschewismus". Zumindest für die Gruppen Gegner und Schwarze Front ist die durch den Titel suggerierte Nähe zum Kommunismus jedoch unzutreffend. Zum Tatkreis siehe auch Fritzsche, Politische Romantik. Zum Gegner vgl. Coppi, Schulze-Boysen. Zur Strasser-Bewegung siehe Moreau, Nationalsozialismus von links.
}

40 Vgl. Sontheimer, Der Tatkreis, S. 229-260.

${ }^{41}$ Vgl. Mohler, Konservative Revolution, Bd. 1, S. $401 \mathrm{ff}$. 
ein enges Netz von personellen Beziehungen zur Folge, die über Schulen, Hochschulen, Bibliotheken, Redaktionen, Verlage und nicht zuletzt die intellektuellen Zirkel und Salons geknüpft wurden. Das Kommunikationsgeflecht war in Frankreich zweifellos schon aufgrund der kürzeren Wege dichter als in Deutschland.

Noch deutlicher als in Deutschland mußte in Frankreich der Umzug in die Hauptstadt als Einschnitt empfunden werden, da dort der Grad der Urbanisierung deutlich geringer war. Während 1930 westlich des Rheins rund 31 Prozent der Bevölkerung in Städten mit über 20000 Einwohnern lebten, waren es östlich des Rheins bereits 43 Prozent. Um so deutlicher war in Frankreich der Kontrast zwischen Provinz und Metropole spürbar: zwar stagnierte die Einwohnerzahl von Paris seit den zwanziger Jahren bei rund 2,8 Millionen (Berlin hatte rund 4 Millionen), doch wuchs das Département Seine seit 1911 jährlich um 1,8 Prozent und erreichte fünf Millionen in den dreißiger Jahren eine Entwicklung, die insbesondere durch den Ausbau der Pariser Banlieue gekennzeichnet $\mathrm{war}^{42}$. Die Vermutung liegt nahe, daß die antiurbanen und antizentralistischen Einstellungen der Nonkonformisten zu einem erheblichen Teil von diesen Großstadterfahrungen geprägt wurden.

Bevor jedoch weitere spezifische Erfahrungshorizonte der Protagonisten erläutert werden, müssen an dieser Stelle zunächst einmal die Ergebnisse der Forschung über die Entwicklung des Bürgertums beiderseits des Rheins ins Auge gefaßt werden. Die ebenso umstrittene wie fruchtbare These vom deutschen Sonderweg hat erheblich dazu beigetragen, die Besonderheiten des deutschen Bürgertums genauer zu erfassen und in eine vergleichende Perspektive einzubetten. Allerdings um den Preis, daß ihre anfänglichen Prämissen weitgehend revidiert werden mußten und es fraglich ist, ob sie überhaupt noch einen Erklärungsanspruch für den Untergang der Weimarer Republik haben kann. Denn ob dies ausdrücklich gesagt wird oder nicht: Der Blickwinkel der Sonderwegsthese war immer der von 1933; die Geschichte des Kaiserreichs wurde im Extremfall auf die Vorgeschichte der Machtergreifung reduziert ${ }^{43}$. Den Maßstab bildete ein zur Norm erhobener Idealtypus einer Entwicklung der westlichen Industrienationen: die Zusammengehörigkeit von wirtschaftlich-industrieller Modernisierung und Demokratisierung. Mittlerweile wird aber selbst von einem ehemals entschiedenen Verfechter wie Hans-Ulrich Wehler die These vom Sonderweg weitgehend relativiert. Von dem geringen gesellschaftlichen Einfluß des Bürgertums und seiner starken Orientierung am Adel ist nicht mehr die Rede. Es bleibt der Befund, daß die politischen Wertvorstellungen des Liberalismus im deutschen Bürgertum in erheblich geringerem Maße verankert waren als in England und Frankreich ${ }^{44}$.

42 Tenfelde, Demographische Aspekte, S. 23; Dupâquier u. a., Histoire, Bd. 4, S. $391 \mathrm{ff}$.; Borne/Dubief, Crise, S. 229; zu den Konservativen Revolutionären vgl. Breuer, Anatomie, S. 27.

${ }^{43} \mathrm{Vgl}$. Nipperdey, 1933, S. 86-111. Anstelle der umfangreichen Literatur über den Sonderweg vgl. die Zusammenfassung der Diskussion bei Grebing, Der „deutsche Sonderweg“.

${ }^{44}$ Wehler, Gesellschaftsgeschichte, Bd.3. An die Stelle der These der "gescheiterten Revolution“ von 1848 tritt die stark personalisierte These von der "charismatischen Herrschaft" Bismarcks als Ausgangspunkt des Sonderweges; vgl. die Besprechung von Evans, Bürgerliche Gesellschaft und charismatische Herrschaft, in: Die Zeit, 13. 10. 1995, S. 32f. Der Vorschlag Kurt Sontheimers, am Sonderweg aus politisch-erzieherischen Gründen festzuhalten, kann so lange nicht überzeugen, wie er auf historische Belege verzichten zu können glaubt; Sontheimer, Une voie allemande, S. 421-426. 
Mit Blick auf Frankreich wird die These vom Sonderweg in einem weiteren Aspekt modifiziert: Das bereits erwähnte Modell der „blockierten Gesellschaft“ von Stanley Hoffmann macht auf vergleichbare strukturelle Hemmnisse in Frankreich aufmerksam. Die soziale Mobilität war durch das prekäre Kräftegleichgewicht zwischen Kleinbürgern und Großbürgertum stark eingeschränkt, aufsteigende soziale Gruppen waren politisch unterrepräsentiert, notwendige Reformen wurden jahrzehntelang verschleppt, und schließlich setzte auch in Frankreich das Zerbrechen der „republikanischen Synthese“ erhebliche extremistische Kräfte frei ${ }^{45}$. Ebenso könnte man daher die Frage diskutieren, ob es auch einen französischen Sonderweg oder ob es nicht vielmehr überhaupt keinen verbindlichen Weg in die Moderne gegeben hat.

Die Einschränkung der These vom deutschen Sonderweg soll nicht besagen, daß es keine Unterschiede zwischen deutschem und französischem Bürgertum in der Zwischenkriegszeit gegeben habe. Sie soll jedoch die Aufmerksamkeit von den langfristigen, strukturellen Ursachen auf die eher kurzfristigen, politischen, wirtschaftlichen und sozialen Ursachen lenken, die im folgenden Abschnitt über die Generationserfahrungen näher untersucht werden. An dieser Stelle ist es zunächst notwendig, das Erbe des 19. Jahrhunderts im Hinblick auf die Situation des Bürgertums beiderseits des Rheins zu skizzieren. Die Gesellschaften beider Länder hatten sich erheblich voneinander entfremdet und wiesen am Vorabend des Ersten Weltkrieges unter allen europäischen Ländern die schärfsten Gegensätze auf. Vor allem die stärker obrigkeitshörige, „unpolitische" Orientierung des deutschen Bürgertums, die unterschiedlichen Wertmaßstäbe von Bildungs- und Wirtschaftsbürgertum und die immer noch dominierende politische Stellung des Adels bleiben als hervorstechende Charakteristika der deutschen Situation bestehen. Das Bildungsethos von Beamten und Freiberuflern, ihr Beharren auf der klassischen, humanistischen Bildung nährte auch Ressentiments gegenüber dem Gewinn- und Wachstumsdenken des Wirtschaftsbürgertums. Eine feindselige Haltung gegenüber der Industriegesellschaft mit ihren neuen sozialen Gruppen, ihren Werten und ihrer Dynamik bildete sich heraus, die das Bildungsbürgertum besonders anfällig für antiliberale Tendenzen machte ${ }^{46}$. In Frankreich war die Machtstellung des Adels schon gegen Ende des 19. Jahrhunderts weitgehend zurückgedrängt, er besaß nur noch auf regionaler

\footnotetext{
${ }^{45}$ Unter diesem Aspekt interpretiert Klaus-Jürgen Müller das Auftreten der extremistischen Bewegungen in den zwanziger und dreißiger Jahren, der Jeunesses Patriotes, des Faisceau, des Redressement français und auch der frühen Solidarité française als Protestbewegungen von Vertretern moderner industrieller Sozialgruppen, die sich für eine stärkere Repräsentation ihrer Interessen einsetzten. Müller betont, daß diese Gruppierungen "nur" eine Reform des parlamentarischen Systems anstrebten und die Dritte Republik nicht grundsätzlich bekämpften. Er stellt jedoch nicht in Rechnung, daß dies auch aus taktischen Überlegungen heraus geschehen sein könnte und daß auch die Nationalsozialisten und die italienischen Faschisten vor ihrer Machtergreifung eine Doppelstrategie von Agitation auf der Straße und der legalen Taktik im Parlament verfolgt haben. Er übersieht weiterhin, daß der Begriff der Republik in Frankreich eine Leerformel war, die zum rhetorischen Bekenntnis gehörte, aber inhaltlich von liberalen bis zu totalitären Positionen alles bezeichnen konnte, was nicht monarchistisch war. Dieses weite Verständnis von Reformbestrebungen führt ihn zu der Schlußfolgerung, daß es bis auf Bucards Francisme keine radikal-antidemokratische und damit faschistische Bewegung in Frankreich gegeben habe; vgl. Müller, Protest, S. 465-524; ders., French Fascism, S. 75-107; ders., Ambition, S. 229-244; zum Begriff des Republikanismus vgl. Wirsching, Nationale Geschichte, S. 181; vgl. Soucy, Second Wave, S. 311.

${ }^{46}$ Ringer, „Bildung“, S. 193-202; Nipperdey, Deutsche Geschichte Bd. 2,1, S. $382 \mathrm{ff}$.
} 
Ebene bestimmenden politischen Einfluß. In Armee und Verwaltung besetzten seit dem Beginn des zwanzigsten Jahrhunderts bürgerliche Beamte die Spitzenpositionen ${ }^{47}$. Allerdings gab es, wie ich im folgenden erläutern möchte, auch in Frankreich die Polarisierung von Bildung und Besitz. Kinder aus dem Großbürgertum waren im Vergleich zu Kindern von Beamten und Akademikern in freien Berufen beim baccalauréat ${ }^{48}$ unterrepräsentiert, noch seltener waren sie an den Hochschulen vertreten.

$\mathrm{Zu}$ den sozialen Codes der bürgerlichen Ausbildung gehörte in beiden Ländern der Besuch humanistischer Bildungsanstalten. Ebenso wie die Konservativen Revolutionäre gehörten die französischen Intellektuellen zur winzigen Bildungselite ihres Landes. Die in der Schule erworbene Bildung war - wie auch in Deutschland - das geistige Fundament einer politisch-sozialen Führungsschicht. Nur rund ein Prozent aller Jugendlichen in Deutschland erhielt zwischen 1885 und 1911 das Reifezeugnis, ganz ähnlich waren die Verhältnisse in Frankreich ${ }^{49}$.

Einen entscheidenden Vorsprung hatte Frankreich in der Vermittlung liberaler Grundsätze durch die Reform des Erziehungssystems in den achtziger Jahren des 19. Jahrhunderts. Jules Ferry hatte mit der Einführung der unentgeltlichen, obligatorischen und staatlichen Volksschule den Kampf gegen die katholischen Schulen eröffnet und den Grundstein gelegt für eine breite Verankerung republikanisch-laizistischer Ideale in der Bevölkerung50. In Deutschland hingegen setzte sich das neue Politikverständnis innerhalb der Pädagogik in den zwanziger Jahren nur langsam durch, so daß sich Schulen und Hochschulen sehr zögerlich zu Vermittlungsinstanzen der neuen Werte entwickelten. In der Zwischenkriegszeit war also in Frankreich ein großer Teil insbesondere der jüngeren Bevölkerung mit liberalen Ideen bereits aus der Schulzeit vertraut, während in Deutschland noch häufig antidemokratische Gedanken verbreitet wurden ${ }^{51}$.

Wenn man die Zugangsbeschränkungen betrachtet, so waren die Unterschiede im höheren Schulwesen in Frankreich und Deutschland/Preußen gegen Ende des 19. Jahrhunderts gering. In beiden Ländern war der höhere Schulbesuch kostenpflichtig, daher bildete - von Stipendiaten abgesehen - ein materieller Wohlstand die Voraussetzung für das Abitur. Auch die hohe Wertschätzung, die dem humanistischen Bildungsideal entgegengebracht wurde, kennzeichnete die Einstellung des Bürgertums beiderseits des Rheins. Gerade der Erwerb zweckfreien Wissens diente zur sozialen Abgrenzung - ein Befund, der sich auch statistisch niederschlug: Die höheren gebildeten Mittelschichten waren unter den Abiturienten am stärksten überrepräsentiert, an zweiter Stelle folgte das Wirtschaftsbürgertum ${ }^{52}$.

Während ein Großteil der künftigen Konservativen Revolutionäre die Bildungsanstalten durchlief, befand sich das Bildungssystem in Deutschland in einer Um-

\footnotetext{
${ }^{47}$ Kaelble, Nachbarn am Rhein, S. 110ff., 139ff.

48 Vergleichbar mit dem deutschen Abitur.

${ }^{49}$ In den Jahren 1885-1887 waren es $0,8 \%$ in Deutsches Reich gegenüber 1,0\% in Frankreich. Zwischen 19010/1911 waren es $1,2 \%$ (Deutsches Reich) gegenüber 1,1\% (Frankreich). Für die zwanziger Jahre existieren keine Zahlen; vgl. die Tabelle bei Ringer, Fields, S. 48.

50 Prost, Histoire, S. $383 \mathrm{ff}$.

51 Vgl. Ringer, Die Gelehrten, S. 358ff.

52 Ringer, Fields, S. $58 \mathrm{ff}$.
} 
bruchphase. Die Gymnasien verloren immer mehr ihre Monopolstellung. Seit 1900 konnten auch die Schüler der Realgymnasien und Oberrealschulen die Berechtigung zum Studium erwerben. Der Anteil der Gymnasien an den höheren Schulen schrumpfte von fast drei Viertel im Jahr 1882 auf etwas mehr als die Hälfte im Jahr 1914. Die humanistische Bildung, die für das Bürgertum von identitätsstiftender Bedeutung war, bildete nicht mehr die einzige Zugangsberechtigung zum Studium. Damit wurde das exklusive Sozialprestige humanistischer Bildung noch vor dem Weltkrieg entschieden in Frage gestellt ${ }^{53}$.

In Frankreich sorgte das Schulsystem weiterhin für die soziale Trennung von Unterschichten und Bürgertum. Eine institutionalisierte Barriere stellte die Zweiteilung des Systems zwischen den Elementarschulen und den weiterführenden Schulen dar. Hier handelte es sich nicht um aufeinander folgende, sondern um parallele Ausbildungen, die einen Wechsel unmöglich machten. Abgesehen von einem gewissen Prozentsatz an Stipendiaten (12 bis 13 Prozent - allerdings in den meisten Fällen Beamtenkinder) war der Besuch der höheren Schule, dem Lycée, fast ausschließlich den Kindern aus dem mittleren und höheren Bürgertum vorbehalten, die damit die Zugangsberechtigung für die Hochschulen erwarben. Diese für die Dritte Republik charakteristische Zweiteilung des Schulsystems wurde auch seit Mitte der zwanziger Jahre nur geringfügig durch eine Elitenauslese modifiziert, die sich stärker an den Fähigkeiten als an der Herkunft orientierte $^{54}$. Ähnlich wie in Deutschland wurde auch westlich des Rheins das humanistische Bildungsmonopol in Frage gestellt. Ein 1902 verabschiedetes Dekret ließ für die siebenjährige höhere Schule nun auch die Wahl moderner Sprachen zu. Doch blieb weiterhin die Kombination Latein/Griechisch diejenige mit dem höchsten Prestige, was die Schüler aus bürgerlichen Familien weiterhin begünstigte ${ }^{55}$. Dies zeigte sich auch in der Zulassung zu den Grandes Ecoles. Für die Aufnahmeprüfung der Ecole Normale Supérieure (ENS) genügte zwar seit 1904 der Nachweis von Latein- oder Griechisch-Kenntnissen, dennoch blieben Latein und Griechisch weiterhin die meistgewählten Prüfungsfächer ${ }^{56}$. Damit blieb das humanistische Bildungsideal trotz der Reformversuche das weitgehend unangetastete Privileg des Bürgertums.

Die Absolventen der Hochschulen besetzten die höheren Ränge in den durch Bildung erreichbaren Posten. Die Nonkonformisten hatten ebenso wie die meisten Konservativen Revolutionäre ein Studium absolviert. Vergleichbar war auch die Vorliebe für geisteswissenschaftliche Disziplinen wie Philosophie, Philologie, Geschichte und Jura. In Frankreich gehörten dazu auch die Absolventen der politischen Wissenschaften, der traditionellen Ausbildung für den diplomatischen Dienst. Weniger stark vertreten waren die Absolventen der Wirtschaftswissenschaften. Werner Sombart und sein Schüler Ferdinand Fried waren Nationalökonomen von hohem Rang, die nicht nur bei den Nonkonformisten Anerkennung fanden ${ }^{57}$. Ihr Einfluß reichte weit über die Kreise der Kon-

${ }^{53}$ Kraul, Das deutsche Gymnasium, S. 116.

${ }^{54}$ Becker/Berstein, Victoire, S. 294f., 358ff.; Ringer, Fields, S. 189ff.; ders., Education, S. $118 f$.

55 Ringer, Fields, S. 43.

56 Smith, The Ecole Normale Supérieure, S. 23.

${ }^{57} \mathrm{Zu}$ Sombart vgl. Aron/Dandieu, La révolution nécessaire, S. 3, 290; zu Fried vgl. Marc, Communisme national, in: Revue d'Allemagne, H. 60 (1932), S. 849-867; ders., L'Etat fermé, in: Revue d'Allemagne, H. 63 (1933), S. 1-19. 
servativen Revolution hinaus ${ }^{58}$. Louis Salleron war der Korporatismus-Experte der Jeune Droite. Er lehrte seit 1937 Wirtschaftspolitik am Institut Catholique ${ }^{59}$. Robert Loustau und Robert Gibrat, die Wirtschaftsexperten des Ordre Nouveau, stammten aus dem Studienkreis X-Crise der Ecole Polytechnique, der insbesondere durch seine neoliberalen Wirtschaftsmodelle großen Einfluß auf die nonkonformistische Generation ausübte ${ }^{60}$. Seltener hingegen waren Absolventen naturwissenschaftlicher und technischer Studiengänge ${ }^{61}$. Deutlich wird an dieser Verteilung der Studienfächer die hohe Wertschätzung bildungsbürgerlicher Ideale. Davon zeugt auch die große Zahl der höheren akademischen Weihen, der Promotion und der Agrégation ${ }^{62}$.

Die bildungsbürgerlichen Privilegien wurden in Deutschland durch die Schul- und Hochschulreformen seit dem Ende des 19. Jahrhunderts ernsthaft in Frage gestellt. Mit dem enormen Anstieg der Studentenzahlen seit den 1890er Jahren und dem einhergehenden Bedeutungsverlust humanistischer Bildung klaffte die Schere zwischen Bildung und Beruf immer weiter auseinander. Eine vergleichbare krisenhafte „Entwertung" bürgerlicher Ideale gab es in Frankreich nicht. Zwar stiegen westlich des Rheins im Zuge der großen Reform im letzten Viertel des 19. Jahrhunderts die Schüler- und Studentenzahlen rapide an, doch scheint dieser Prozeß mit geringeren Reibungsverlusten über die Bühne gegangen zu sein. Gleichzeitig wurden seit 1880 die Hochschulen umgestaltet und erheblich erweitert. Dienten die Fakultäten bis dahin in erster Linie der Vorbereitung auf den baccalauréat und der Lehrerausbildung, so wurden sie nun $\mathrm{zu}$ wissenschaftlichen Anstalten nach dem „deutschem Modell“ ${ }^{63}$. In den akademischen Fakultäten (Literatur, Naturwissenschaften) vervierfachte sich die Zahl des Lehrpersonals zwischen 1870 und 1910, die Zahl der Studenten vergrößerte sich seit 1880 rasant: Innerhalb von zwei Jahrzehnten übertraf Frankreich seinen östlichen Nachbarn gemessen an den relativen Studentenzahlen (im Verhältnis zur jeweiligen Altersklasse): 1885-1887 waren es 0,6 Prozent westlich und 0,8 Prozent östlich des Rheins, 1910-1911 schon 1,7 Prozent gegenüber 1,2 Prozent und schließlich 1930-1931 sogar 2,9 Prozent gegenüber 2,1 Prozent ${ }^{64}$.

${ }^{58}$ Fried, eigentlich Ferdinand Friedrich Zimmermann, war der Wirtschaftsspezialist des Tatkreises, vgl. Mohler, Konservative Revolution, Bd. 1, S. 435; zu Sombart vgl. Lenger, Sombart.

59 Vgl. Dioudonnat, Rédacteurs, S. 81; Coston, Dictionnaire, Bd. 1, S. 956.

to Zu diesem Studienkreis gehörte auch der Statistiker Alfred Sauvy, vgl. Abellio [d. i. Georges Soulès], Ma dernière mémoire, Bd.2, S. $101 \mathrm{ff} . ;$ Brun, Technocrates, S. 33ff.

${ }^{61}$ Aus dem Kreis der Konservativen Revolutionäre: Spengler: Mathematiker, Ernst Jünger: Naturwissenschaften; bei den Nonkonformisten: Chevalley: Mathematiker, Gibrat und Loustau: Ingenieure.

62 Einen dem deutschen Doktor vergleichbaren Abschluß gab es in Frankreich nur in Jura und Medizin (Doctorat d'université). Wenn man aber die Agrégation als vergleichbare Voraussetzung für eine universitäre Karriere hinzuzählt, so ergibt sich ein ähnliches Bild. Promovierte in Deutschland: Spengler, Stapel, Freyer, Schmitt, Jung, Spahn, Ziegler, von Gleichen, Brauweiler, Stadtler, Boehm, F. G. Jünger, Eschmann, Hielscher, vgl. Breuer, Anatomie, S. 30. Agrégation/Doctorat in Frankreich (soweit sich dies rekonstruieren ließ): Chevalley, Chenut, Jardin; Agrégation: Aron, Brasillach, Daniel-Rops, Dupuis, Gravier, Salleron. Die Agrégation unterscheidet sich insofern vom deutschen Doktor, als sie anstelle einer Dissertation eine staatliche Prüfung erforderte. Im schnellsten Fall erlangte man sie nach drei Jahren auf der Ecole Normale Supérieure; Karady, Teachers, S. 472f.; Ringer, Fields, S. 44.

${ }^{63}$ Ringer, Fields, S. $46 f$.

${ }^{64}$ Ringer, Education, S. 120; Karady, Teachers, S. 484ff. 
Auch in Frankreich wurde die Gefahr der „Plutokratisierung“ beschworen, insbesondere von Kritikern aus dem rechten Lager, die die ideologischen Implikationen des „wissenschaftlichen Materialismus“ denunzierten und das Ende des klassischen Bildungskanons beklagten. Die traditionell deutschfeindliche Rechte fürchtete zudem eine „Germanisierung" der französischen Kultur durch die Reform, die sich am deutschen Universitätssystem orientierte ${ }^{65}$. Dennoch verlief die Reform insgesamt nicht mit so einschneidenden Identitätskrisen wie in Deutschland. Vielmehr hob sie erst die Universitäten auf ein mit Deutschland vergleichbares wissenschaftliches Niveau, verbesserte Ansehen und Ausbildung der Akademiker erheblich und eröffnete ihnen bessere Berufschancen. Allerdings wurde durch die gewaltige Expansion das bürgerliche Bildungsprivileg auch in Frankreich erheblich in Frage gestellt ${ }^{66}$.

Eine dem französischen System vergleichbare Zweiteilung des Hochschulsektors gab es in Deutschland nicht, daher bedarf diese Besonderheit der Erläuterung. Die Spitzenpositionen in Politik und Verwaltung besetzten nahezu ausschließlich die Absolventen der Grandes Ecoles. In diese Elitehochschulen konnte man frühestens nach einem zweijährigen Vorbereitungskurs an einigen dazu bestimmten Lycées aufgenommen werden (bypokhâgne/khâgne für den sprachlichen, taupe für den naturwissenschaftlichen Zweig). Die eigentliche Hürde aber bildete die Eingangsprüfung, durch die im Fall der ENS jährlich die 30 besten Studenten in jedem der beiden Zweige (Sprachen/Naturwissenschaften) ausgewählt wurden. Auch hier hatte Paris mit seinen vier Vorbereitungsschulen (Condorcet, Lakanal, Louis-le-Grand und Henri-IV) bei der Zahl der erfolgreichen Aufnahmen gegenüber der Provinz einen deutlichen Vorsprung: während der zwanziger Jahre stammten rund drei Viertel der Stipendiaten aus den Pariser Schulen, während sich der Rest auf die 15 Provinz-Lycées verteilte. Wer also nur eine halbwegs realistische Chance auf einen der begehrten Plätze in den Grandes Ecoles haben wollte, mußte die Vorbereitungsklassen in Paris, möglichst am Henri-IV oder Louis-le-Grand, absolvieren ${ }^{67}$. Es ist daher nicht sonderlich erstaunlich, daß sich ein großer Teil der freundschaftlichen Beziehungen unter den Nonkonformisten schon dort während der Vorbereitungsklassen herausgebildet hat ${ }^{68}$. Der Ausleseprozeß der Grandes Ecoles förderte zudem mit seinen speziellen Konsekrationsriten eine Gruppenidentität, die über

${ }^{65}$ Insbesondere von Henri Massis und Alfred de Tarde, die 1912 ihre erste Kampagne gegen die Reform der "neuen Sorbonne" führten, vgl. Ringer, Fields, S. 237ff.

${ }^{66}$ Prost, Histoire, S. 243. Zur Situation in Deutschland: Jarausch, Studenten, S. 76ff.

${ }^{67}$ Vgl. Sirinelli, Génération intellectuelle, S. 67ff., Übersicht S. 70 und ders., Aux lisières, S. $19 \mathrm{ff}$.

${ }^{68}$ Den hohen Stellenwert der Vorbereitungsklassen für die Bildung dauerhafter Freundschaften betont auch Sirinelli in seinen Arbeiten über die Ecole Normale Supérieure. In der Tat kann man anhand der Nonkonformisten dieses Phänomen verfolgen: am Louis-le-Grand, der bedeutendsten Vorbereitungsschule, lernte sich ein Teil des Esprit-Kreises kennen: Georges Izard, André Déléage und Pierre-Henri Simon. Emmanuel Mounier stieß später an der Ecole Normale Supérieure hinzu. In den Vorbereitungsklassen dieser Schule kamen auch Robert Brasillach, Maurice Bardèche und Thierry Maulnier erstmals zusammen; Sirinelli, Génération, S. 71, ders., Aux lisières, S. $111 \mathrm{ff}$. Robert Aron und Arnaud Dandieu hingegen, die späteren Mitbegründer des Ordre Nouveau, schlossen schon vor dem Krieg am Condorcet Freundschaft; Sirinelli, Génération, S. $95 f$. 
das Studium hinaus dauerhafte Verbindungen schuf69. Die Absolventen der Grandes Ecoles besetzten sämtliche Spitzenpositionen in Wirtschaft, Verwaltung und Unterricht. Unter ihnen spielten besonders die Ecole Polytechnique und die ENS eine herausragende Rolle.

Die Ecole Polytechnique, die Grande Ecole zur Herausbildung des Ingenieursnachwuchses, unterstand bezeichnenderweise nicht dem Erziehungs-, sondern dem Kriegsministerium. Sie war der Hort der vorrepublikanischen Eliten aus den Kreisen der Notabeln und des Großbürgertums. Aus ihren Reihen kamen die Verteidiger des klassischen Curriculum und entschiedensten Gegner der großen Reformen des Erziehungssystems. Den Absolventen der Polytechnique waren die höchsten Posten in Militär, Verwaltung (insbesondere im Kriegsministerium) und Wirtschaft reserviert. Hier waren die Studenten aus dem höheren Bürgertum weit überrepräsentiert: Unter den Vätern fanden sich besonders viele Unternehmer aus Handels- und Finanzkreisen sowie einige Industrielle $^{70}$. Von dieser Hochschule stammten die Ordre Nouveau-Mitarbeiter Robert Loustau und Robert Gibrat ${ }^{71}$.

Die privilegierte Ausbildungsanstalt für das Lehrpersonal an höheren Schulen und Universitäten war die Ecole Normale Supérieure an der Rue d'Ulm. Auch sie war im Zuge der großen Reform zu einer republikanischen Hochschule umgestaltet worden. Seit 1903 wieder mit der Sorbonne vereinigt, teilten die Normaliens ${ }^{72}$ die meisten ihrer Kurse mit den Kommilitonen der Universität von Paris ${ }^{73}$. Im Unterschied zur Ecole Polytechnique hatte dort das Bildungsbürgertum eine starke Stellung. Studenten aus Beamtenfamilien waren zehnmal stärker vertreten als solche aus dem Wirtschaftsbürgertum. Die Unternehmer hielten es nicht für sonderlich attraktiv, in den Staatsdienst zu treten. In bezug auf die Gesamtbevölkerung waren Söhne ${ }^{74}$ von Lehrern und Beamten im Erziehungswesen sogar im Verhältnis 35 zu 1 vertreten ${ }^{75}$. Viele dieser Normaliens erreichten den Höhepunkt eines sozialen Aufstiegs über mehrere Generationen von Beamten. Sowohl im Fall der Polytechnique als auch der ENS führte die Reform nicht zu einer Demokratisierung, sondern vielmehr zu einer stärkeren Förderung des Eliten-Bewußtseins. Man muß noch einmal innerhalb der beiden Studiengänge unterscheiden. Der naturwissenschaftliche Zweig der ENS war derjenige mit dem geringeren Prestige. In diesem Bereich war die ENS nur zweite Wahl nach der Polytechnique, was sich auch in der sozialen Schichtung ablesen ließ. Deutlich stärker als dort und auch stärker als im sprachlichen Zweig der ENS waren dort die Söhne von Lehrern, Kleinhändlern und Handwerkern vertreten. Der sprachliche $Z$ weig hingegen führte in die Spitzenpositio-

69 Vgl. dazu die Erinnerungen eines Normalien: Peyrefitte, Rue d'Ulm, und die Untersuchung von Pierre Bourdieu, die sich zwar auf die Gegenwart bezieht, aber weitgehend konstante Verfahren beschreibt: Bourdieu, Epreuve scolaire, S. 30ff.

70 Ringer, Education, S. 139f.; Smith, Ecole Normale Supérieure, S. 35f.; Shinn, Rectionary Technologists, S. 329-345.

71 Vgl. Andreu, Revoltés, S. 41.

72 Studenten und Absolventen einer Ecole Normale Supérieure.

${ }^{73}$ Ringer, Fields, S. 214.

${ }^{74}$ Die ENS an der Rue d'Ulm war für den männlichen Nachwuchs bestimmt. Nur ausnahmsweise wurden Studentinnen (Simone de Beauvoir, Simone Weil) zugelassen.

75 Dies bezieht sich auf den Mittelwert aus der gesamten Dritten Republik, genauer gesagt der Jahre 1868 bis 1941; Smith, Ecole Normale Supérieure, S. 34ff. 
nen von Lehre, Forschung und Verwaltung des Erziehungswesens und darüber hinaus in der Zwischenkriegszeit häufig in die Politik ${ }^{76}$. Zu den Absolventen des sprachlichen Zweiges der ENS gehörten Thierry Maulnier und Robert Brasillach von der Jeune Droite, den naturwissenschaftlichen Zweig hatte Claude Chevalley vom Ordre Nouveau absolviert ${ }^{77}$. Zur gleichen Altersklasse gehörten später so prominent gewordene Intellektuelle wie Raymond Aron, Simone de Beauvoir, Maurice Merleau-Ponty, Paul Nizan, Jean-Paul Sartre und Simone Weil. Die Liste der aufgenommenen Kandidaten liest sich wie ein Who is who der französischen Intellektuellenszene ${ }^{78}$.

Die Ecole Libre des Sciences Politiques war bis zum Ende des Zweiten Weltkrieges eine Privatschule und ließ als solche nur Studenten aus einem entsprechend begüterten Elternhaus zu. Sie hatte nahezu das Ausbildungsmonopol für die hohen Verwaltungsposten und den diplomatischen Dienst ${ }^{79}$. Hier lernten sich der Gründer des Ordre Nouveau, Alexandre Marc, und zwei seiner künftigen Mitarbeiter, Jean Jardin und René Dupuisé, kennen. $\mathrm{Zu}$ Beginn der dreißiger Jahre absolvierte auch Xavier de Lignac diese Laufbahn, bevor er 1934 zum Ordre Nouveau stieß80.

Wer die Aufnahmeprüfung für die Grandes Ecoles nicht schaffte, für den blieben immer noch die Universitäten. Durch die große Hochschulreform wurde die Sorbonne neben der ENS zu dem wichtigsten Stützpfeiler des republikanischen Systems. Die Reform hatte klare politische Implikationen: Nach den Vorstellungen des Reformers Gustave Lanson sollten die Studenten der neuen Sorbonne vor allem einen Sinn für die republikanischen Tugenden, Wahrheit, Gerechtigkeit, Solidarität und bürgerliche Gesinnung, entwickeln ${ }^{81}$. Dies war von besonderer Bedeutung, da die Absolventen in den meisten Fällen als Lehrer in dem ebenfalls reformierten laizistischen Schulwesen arbeiten sollten. Gerade an der Sorbonne aber waren die antiliberalen Studenten ebenfalls stark vertreten. Ein großer Teil der Jeune Droite stammte von ihr: Jean de Fabrègues, François Gravier, Jean-Pierre Maxence, Claude Roy und René Vincent. Auch Robert Aron hatte nach der gescheiterten Aufnahme in die ENS dort seine Agrégation vorbereitet.

Gegenüber ihren Kollegen von den Provinzuniversitäten genossen die Absolventen der Pariser Hochschulen ein erheblich höheres Prestige. Auch nach der Reform war ein vergleichbarer Abschluß in der Provinz deutlich weniger angesehen. Der Zentralismus schlug sich auch in den Verdienstmöglichkeiten nieder. So wurden Lehrer und Professoren in der Provinz unverhältnismäßig schlechter bezahlt als solche mit einer Anstellung in Paris. Für Absolventen mit einem Provinzabschluß war es dementsprechend schwer, eine Anstellung in der Hauptstadt zu finden ${ }^{82}$. Daher ist es kaum verwunderlich, daß nur sehr wenige unter den Nonkonformisten ihre Ausbildung in der Provinz oder im Ausland absolviert hatten, bevor sie nach Paris kamen: Daniel-Rops ${ }^{83}$ hatte seine Agrégation

\footnotetext{
${ }^{76}$ Smith, Ecole Normale Supérieure, S. 38ff.

77 Sirinelli, Génération intellectuelle, S. 96, 312f.

${ }^{78} \mathrm{Vgl}$. Sirinelli, Génération intellectuelle, S. 647ff.

${ }^{79}$ Ringer, Fields, S. 44.

${ }^{80}$ Assouline, Eminence grise, S. 27, 38; Roy, Marc, S. 138f.; zu Lignac vgl. Ganne, Qu'as-tu fait, S. 8.

${ }^{81}$ Ringer, Fields, S. $225 \mathrm{ff}$.

82 Karady, Teachers, S. 490f.; Prost, Histoire, S. 357f.

${ }^{83}$ Pseudonym für Henri Petiot. Zur Biographie vgl. Dournès, Daniel-Rops, S. $26 \mathrm{ff}$.
} 
in Geschichte an der Universität Poitiers abgeschlossen ${ }^{84}$. Denis de Rougemont hatte in Neuchâtel, Wien und Genf Literatur und Sprachen studiert ${ }^{85}$, Robert Castille (Jeune Droite) hatte seine Licence in Jura in Dijon erworben ${ }^{86}$.

Für die Nonkonformisten ergab sich ebenso wie für die Konservativen Revolutionäre die paradoxe Situation, daß sie eine zutiefst bürgerliche Sozialisation durchlaufen hatten, daß sie durchdrungen waren von dem Gedanken der meritokratischen Elitenauslese, zugleich aber die Wertmaßstäbe des Bürgertums radikal bekämpften. Ihre Kritik galt nicht den Errungenschaften und Werten der abendländischen Kultur, sondern vielmehr der sozialen Klasse, die sich als Trägerin dieses kulturellen Erbes betrachtete, und der Ideologie, die in den Augen der jungen Intellektuellen ihren Herrschaftsanspruch legitimierte: dem Liberalismus. Die Auswahlverfahren des Bildungssystems hatten sie zutiefst geprägt: sie bejahten die Elitenrekrutierung und den Leistungsgedanken, bestritten aber die Eignung des Bürgertums zur politischen Führung, auf die sie selbst Anspruch erhoben.

\section{Generationserfahrungen und Jugendkult}

Robert Wohl hat in seiner Pionierstudie über die "Generation von 1914“ die Bedeutung des Weltkrieges als zentraler Epochenschwelle untersucht. Erstmals hat er nachgewiesen, wie durch ihn eine Generation von Intellektuellen in ganz Europa in ihren kulturkritischen und antiliberalen Denkhaltungen entscheidend geprägt wurde. Zwischen 1880 und 1900 geboren, sind diese Intellektuellen aufgewachsen in der Opposition gegen die bürgerliche Wertordnung ihrer Väter, begrüßten enthusiastisch den Krieg als Beginn des ersehnten Aufbruchs und wurden schließlich in ihren Hoffnungen von der Realität des Fronterlebnisses und der Nachkriegszeit tief enttäuscht. Zu jung für die alte Welt und zu alt für die neue, haben diese „Wanderer zwischen zwei Welten" 87 den im Krieg geborenen Traum einer politischen und kulturellen Erneuerung in die zwanziger Jahre hinübergerettet ${ }^{88}$. Als Ausdruck einer tiefen Identitätskrise entstanden - wie Wohl am Beispiel von Frankreich, Deutschland, England, Spanien und Italien gezeigt hat -, insbesondere in der Zwischenkriegszeit, die Vorstellungen von einem Konflikt der Generationen, in dem die Ideologie der Jugend eine zentrale Rolle spielte. Bereits vor 1914 war der Begriff der "Jugend“ in seiner Semantik von Erneuerung, Auflehnung, Dynamik und Charisma geprägt, doch seine spezifisch politische Stoßkraft hat er meist erst durch den Krieg erhalten: die Idee einer gemeinsamen Bestimmung, die Sehnsucht nach einer klassenübergreifenden Gemeinschaft hatte als Orientierungspunkt die Nation, die durch äußere und innere Feinde bedroht war ${ }^{89}$.

$\mathrm{Zu}$ Recht betont Wohl, daß dieses Generationskonzept stark durch den Erfahrungshorizont der Frontkämpfer geprägt war, die durch die Epochenschwelle des Weltkrieges

\footnotetext{
${ }^{84}$ Sirinelli, Génération intellectuelle, S. 112.

${ }^{85}$ Ackermann, Rougemont, Bd. 1, S. $74 \mathrm{ff}$.

${ }^{86}$ AN F7 13 983, Bericht vom Mai 1936.

87 Dies ist der Titel einer 1917 erschienenen Schrift von Walter Flex.

88 Wohl, Generation, S. $203 \mathrm{ff}$.

${ }^{89}$ Ebenda, S. $215 f$.
} 
in eine fundamentale geistige Orientierungskrise geraten waren. Daraus sind die grundlegenden Theorien des sozialen Wandels entstanden, die die treibende Kraft nicht mehr im Kampf der Klassen, sondern im Konflikt zwischen Vätern und Söhnen angelegt sehen: von José Ortega y Gasset, François Mentré, Eduard Wechssler und Karl Mannheim ${ }^{90}$.

Mit der Politisierung der "Jugend" erkannten auch Parteien, Verbände und Kirchen die Notwendigkeit, diese Aufbruchstimmung zu kanalisieren. Davon zeugt die rapide anwachsende Zahl von Jugendorganisationen in den zwanziger Jahren. Von der neueren Forschung ist insbesondere die Vorstellung von den „individualistischen“ Franzosen korrigiert worden ${ }^{91}$.

Eine besondere Anziehungskraft auf die Jugend übten vor allem die extremistischen Bewegungen und Parteien aus. Die militaristischen Kampfbünde der Weimarer Zeit rekrutierten ihre Gefolgschaft überwiegend aus Altersgruppen der 20- bis 30jährigen ${ }^{92}$. Auch die Nationalsozialisten hatten ebenso wie die Kommunisten sowohl im Verhältnis zum Bevölkerungsdurchschnitt als auch im Vergleich mit anderen Parteien bis 1933 eine ausgesprochen junge Anhängerschaft ${ }^{93}$. Über die Altersstruktur in den französischen Ligen gibt es zwar keine Untersuchungen, doch läßt sich dort eine ähnliche Überrepräsentation von jungen Anhängern vermuten. Insbesondere die Action française hatte sich den Jugendmythos zu eigen gemacht. Ihre Schüler- und Studentenorganisationen gehörten bis zur Mitte der zwanziger Jahre zu den mächtigsten in Frankreich94. Die Jeunesses Patriotes von Pierre Taittinger verdeutlichten den Anspruch auf diese Zielgruppe bereits durch ihren Namen. Weitere Anhaltspunkte liefert die Entwicklung der Feuerkreuzler: Die Bewegung erhielt erheblichen Zulauf, nachdem ihr Anführer François de la Rocque 1933 mit der Sektion der Nationalvolontäre (Volontaires Nationaux) ein Sammelbecken für junge Männer unter 21 Jahren geschaffen hatte ${ }^{95}$.

Auch die Protagonisten der Konservativen Revolution und der Nonkonformisten waren zu Beginn ihres Engagements meist Ende Zwanzig bis Anfang Dreißig, selten älter. Ihre Jugendideologie formulierten sie häufig in der Form eines „Dritten Weges“: jenseits von Kapitalismus und Kommunismus, zwischen West und Ost, Liberalismus und Kollektivismus. Diese Bestrebungen fanden unterschiedlichen Ausdruck: in Buchtiteln wie Die Sendung der jungen Generationen von Ernst Günther Gründel, Das Recht der jungen Völker von Moeller van den Bruck, in Zeitschriften wie den Jungpolitischen Rundbriefen (1928-1929) von Richard Schapke und Karl Otto Paetel, in Organisationen wie dem Jungdeutschen Orden von Arthur Mahraun und den Jungkonservativen. Der Tatkreis hat mit dem Jugendmythos eine Strategie entwickelt, die als repräsentativ für die Konservative Revolution überhaupt angesehen werden kann: Sie zielte auf die Überwindung der politischen Lager, die in die Bildung einer „Dritten Front“ münden sollte. In seinem Grundsatzartikel „Rechts oder Links?“ forderte der Chefredakteur der Tat,

\footnotetext{
90 Ebenda, S. 2f., 208f.; vgl. Trommler, Mission ohne Ziel, S. 22.

${ }^{91}$ Krabbe, Die gescheiterte Zukunft; Götz von Olenhusen, Jugendreich; Fabre, Les mouvements de jeunesse, S. 9-30; Prost, Jeunesse, S. 35-43.

${ }_{92}$ Vgl. Peukert, Alltagsleben, S. 148; Jamin, Zwischen den Klassen.

${ }^{93}$ Kater, Generationskonflikt, S. 231.

${ }^{94} \mathrm{Vgl}$. Weber, Action française, S. 172ff., bes. $179 \mathrm{f}$.; Reichel, Nationalismus, S. $152 \mathrm{f}$.

${ }^{95}$ Soucy, Second Wave, S. $109 f$.
} 
Hans Zehrer, in Anlehnung an Georges Sorel die Schaffung eines neuen Mythos, der die beiden Extreme des politischen Spektrums in einer neuen Synthese vereinen und das Ideal der neuen Volksgemeinschaft begründen sollte ${ }^{96}$. Ähnliche Vorstellungen von der revolutionär-chiliastischen Überwindung der verfeindeten Lager finden sich in den Kreisen der Konservativen Revolution von Spengler bis Niekisch"7.

Für die Nonkonformisten wurde das Bewußtsein der eigenen Jugend ebenfalls zur integrierenden Schlüsselerfahrung. Gegen den Zerfall der Gesellschaft in Interessengruppen sollte die Jugend eine neue Einheit herstellen: „Zwei große Lager bilden sich heraus, die die westliche Zivilisation horizontal in Generationen spalten: das individualistischdemokratische Lager, das dem 19. Jahrhundert entstammt. [...] Und das Lager der Jugend. "98 Dabei war jedoch weniger das biologische Alter als vielmehr die Geisteshaltung ausschlaggebend für die Zugehörigkeit: „Es handelt sich nicht um zwei physiologische Altersstufen, die einander bekämpfen, sondern um zwei unterschiedliche Situationen, Atmosphären, zwei einander entgegengesetzte Geisteshaltungen. “99 Ähnliche Bemühungen, die politischen Fronten zu durchbrechen, mehrten sich zu Beginn der dreißiger Jahre im Umkreis der Nonkonformisten: Die von Jean Luchaire geleitete Zeitschrift Notre Temps (1927-1940) nahm für sich in Anspruch, das Organ der „neuen Generationen" zu sein. Sie setzte sich maßgeblich für die Idee der Verständigung zwischen der deutschen und französischen Jugend ein. Aus diesem Kreis stammte auch Bertrand de Jouvenel, der mit der Zeitschrift La Lutte des Jeunes (1934) ein Sammelbecken hauptsächlich für die Intellektuellen der nonkonformistischen Generation schuf, bevor er 1936 zur Doriot-Bewegung stieß100. In dem Werk Le Rajeunissement de la politique meldeten sich Vertreter eines neuen Politikverständnisses zu Wort, die die Parteienherrschaft überwinden wollten: Ramon Fernandez, ein ehemaliger Kommunist, der sich der Doriot-Bewegung anschloß, Marcel Déat, der mit der SFIO brach und sich an die Spitze der Neosozialisten stellte, Jean-Pierre Maxence und Thierry Maulnier aus dem Kreis der Jeune Droite, sowie Daniel-Rops vom Ordre Nouveau ${ }^{101}$.

Die Jugendideologie konnte in den Augen ihrer Verfechter nicht nur soziale und politische Schranken überwinden, sondern auch nationale Gegensätze. Für die Autoren des Bandes Jeune Europe bildete der Generationswechsel die Voraussetzung für eine grenzüberschreitende Verständigung. Die Verfasser Alexandre Marc und René Dupuis gehörten zum Direktionskomitee vom Ordre Nouveau. Sie interpretierten die Umbrüche in Rußland, Italien und Deutschland als das politische Erwachen einer Jugend, die mit den politischen, wirtschaftlichen und sozialen Folgen des Liberalismus brechen wollte. Die beiden Ordre Nouveau-Anhänger bewunderten zwar die Vitalität und Dynamik dieser „Erneuerungsbewegungen“, doch konstatierten sie zugleich deren Scheitern vor der

96 Zehrer, Rechts oder Links?, in: Tat 22 (1931), S. 505-559, hier bes. 525ff.; vgl. ders., Die dritte Front, in: Tat 23 (1932), S. 97-120, hier bes. S. 103ff.; Mommsen, Generationskonflikt, S. 56, 59f.; Trommler, Mission ohne Ziel, S. 42f.

${ }^{77}$ Sieferle, Konservative Revolution, S. 178-205; vgl. Merlio, Oswald Spengler.

${ }^{98}$ Lamour, Jeunesse du monde, in: Plans, H. 4, 1931, S. 9.

${ }^{99}$ Marc, Prise de conscience révolutionnaire, in: Plans, H. 13, 1932, S. 59.

100 Burrin, Dérive, S. 83ff.

101 Le Rajeunissement de la politique, Hrsg. H. de Jouvenel. Der Band war hervorgegangen aus einer Untersuchung von Jouvenel in der Revue des Vivants 1930-1932. 
Aufgabe, die alte Ordnung endgültig zu überwinden. In der Form des Staatskapitalismus (Sowjetunion), des Etatismus (Italien) und der Massendemokratie (Deutschland) blieben ihrer Ansicht nach zentrale Elemente der Ideologie des Liberalismus erhalten. Dupuis und Marc sahen nun die Aufgabe der französischen Jugend gekommen, den revolutionären Impuls aufzugreifen und den Kampf gegen das liberale System zu vollen$\operatorname{den}^{102}$.

Betrachtet man die Geburtsjahrgänge der Akteure in Deutschland und Frankreich, so wird deutlich, daß sich deren Erfahrungshorizonte erheblich unterschieden. Die Konservative Revolution umfaßte eine Spanne von drei politischen Generationen 103: Während die erste durch Reichsgründung, die wilhelminische Zeit und die Jugendbewegung geprägt war ${ }^{104}$, erfuhr die letzte, die sogenannte „überflüssige Generation“, mit aller Deutlichkeit die Schwierigkeiten der Integration in die Gesellschaft: Die Vertreter dieser Altersklasse waren zu jung für den Krieg und trafen in der Weimarer Republik auf einen überfüllten Arbeitsmarkt ${ }^{105}$. Die meisten Konservativen Revolutionäre zählten jedoch zur Frontkämpfergeneration der 1880 bis 1890 Geborenen ${ }^{106}$. Sie prägten einen zentralen Charakterzug der Konservativen Revolution: ihren radikalen Militarismus. Das Fronterlebnis wurde nachträglich zur Geburtsstunde der Nation stilisiert. Der Ausbruch aus bürgerlicher Enge und die Erfahrung der klassenüberschreitenden Gemeinschaft waren die zentralen Themen einer ganzen Flut von Schriften, die den Kampf als inneres Erlebnis verherrlichten und die kriegerische Dynamik des neuen Nationalismus unterstrichen. Ernst Jünger und Franz Schauwecker waren die einflußreichsten Autoren dieser Art von geistiger Mobilmachung gegen die Weimarer Republik ${ }^{107}$.

In Frankreich läßt sich kein vergleichbares Phänomen feststellen. Die Nonkonformisten entstammten zum überwiegenden Teil der Altersklasse von 1900 bis 1910 . Sie gehörten damit zu den ersten Jahrgängen, die nicht mehr an die Front einberufen worden waren - vergleichbar mit der sogenannten „überflüssigen Generation“ in Deutsch-

102 Dupuis/Marc, Jeune Europe, S. $179 \mathrm{ff}$.

${ }^{103}$ Kennzeichnend für dieses Konzept ist die Annahme, daß ein Ereignis von besonderer Tragweite die Denkmuster einer Altersklasse so nachhaltig bestimmt, daß sie auch noch über längere Zeiträume für die politischen Einstellungen und Konflikte prägend sind. Dieser Ansatz ist nicht zu verwechseln mit dem weiter gefaßten Modell einer kontinuierlichen Abfolge von Generationen (meistens in einen Rhythmus von 30 Jahren), bei dem die Rahmenbedingungen, meist demographische Faktoren, jeweils daraufhin untersucht werden, inwieweit sie gesellschaftlich tradierte Lebensentwürfe beeinflussen. Noch zu erwähnen wäre das Generationskonzept als eine rein primäre, d. h. letztlich biologisch verursachte Erscheinung, die aber bei dem hier untersuchten Phänomen kaum eine Rolle spielt. Vgl. allgemein Jaeger, Generationen, S. 429-452; Girardet, Du concept de génération, S. 257-270; Brunschwig, Die historischen Generationen, S. 373-385 und Sirinelli, Concept, S. 82-93.

104 1870er Jahre: Moeller van den Bruck, Spengler, Spahn.

105 1900-1914: Ernst Wilhelm Eschmann, Friedrich Hielscher.

106 Wilhelm Stapel, Hans Freyer, Carl Schmitt, Ernst Niekisch, Edgar Julius Jung, Ernst und Friedrich Georg Jünger, Hans Zehrer, Leopold Ziegler, Heinrich Brauweiler, Eduard Stadtler, Max Hildebert Boehm, Ferdinand Fried; vgl. Breuer, Anatomie, S. 30f.

107 Sontheimer hat diesen zentralen Sachverhalt ausführlich analysiert: Sontheimer, Antidemokratisches Denken, S. 93ff.; Breuer, Anatomie, S. 33ff.; vgl. Mohler, Konservative Revolution, Bd. 1, S. 32ff., $278 f$. 
land ${ }^{108}$. Ihre persönlichen Perspektiven unterschieden sich allerdings fundamental: Während in Deutschland in den Jahren von 1900 bis 1915 der größte überhaupt bekannte Geburtenberg verzeichnet wurde, war die demographische Situation in Frankreich durch eine außerordentliche Stabilität gekennzeichnet ${ }^{109}$. Die Konservativen Revolutionäre dieser Altersklasse durchliefen ihre Ausbildung in überfüllten Schulen und Universitäten, um Ende der zwanziger, Anfang der dreißiger Jahre auf einen ebenso überfüllten Arbeitsmarkt zu stoßen. Unter diesen Bedingungen war es außerordentlich schwer, positive Zukunftserwartungen zu entwickeln. Gerade aus diesem Mangel an Perspektiven erwies sich diese „überflüssige Generation“ als besonders anfällig für extremistische Gruppierungen wie die Kampfbünde. Sie bildeten die Auffangbecken für die Jugendlichen, die der Sinnleere der Arbeitslosenexistenz zu entrinnen versuchten ${ }^{110}$.

Die Nonkonformisten hingegen trafen auf eine für sie verhältnismäßig günstige Konjunktur. Da die Lücken des Krieges noch immer nicht vollständig aufgefüllt waren, gelang es vielen von ihnen, bereits als Berufsanfänger vergleichsweise hohe Stellungen einzunehmen, andere begannen sehr früh ihre publizistische Karriere ${ }^{111}$. Die Gründe für ihr Engagement sind also nicht in der Erfahrung einer persönlichen Perspektivlosigkeit zu suchen, sondern eher in dem Zusammentreffen des geistig-politischen Klimawechsels zu Beginn der dreißiger Jahre mit einer Phase der Neuorientierung zwischen dem Abschluß des Studiums und dem Eintritt in das Berufsleben.

Eine mythische Überhöhung des Kriegserlebnisses wird man in Frankreich auch in der Frontkämpfergeneration vergeblich suchen. Zwar existierte in Frankreich eine Tradition von Kampfbünden, die über autoritäre Organisationsstrukturen verfügten und militärische Tugenden kultivierten. Als politische Agitationsinstrumente richteten sie sich unmittelbar gegen die parlamentarische Demokratie ${ }^{112}$. Aber in keinem Fall knüpften diese Bewegungen in positiver Weise an das Erlebnis des Krieges an. Im Gegenteil, es herrschte in Frankreich ein die politischen Lager übergreifender Konsens darüber, daß ein neuer Krieg um nahezu jeden Preis verhindert werden mußte. Weit verbreitet war die Überzeugung, daß der Krieg eine neue Dimension gewonnen hatte und es somit in einem künftigen Konflikt nur noch Verlierer geben konnte. Angesichts dieser Grundstim-

108 Vgl. Balmand, Jeunes intellectuels, S. 49-64. Blanchot 1907, Blond 1906, Brasillach 1909, Fabrègues 1906, Chevalley 1909, Daniel-Rops 1901, Dupuis 1905, Gibrat 1904, Jardin 1904, Lamour 1903, Marc 1904, Mauban 1907, Maulnier 1909, Maxence 1906, Rougemont 1906, Salleron 1905, Vincent 1909; aus dem Esprit-Kreis: Borne 1907, Izard 1903, Déléage 1904, Galey 1904, Mounier 1905, Simon 1903. Nicht ganz in das Generationsschema passen die Geburtsdaten von Dandieu 1898 und Aron 1897. Letzterer war zudem Offizier im Ersten Weltkrieg.

${ }^{109}$ Im Jahr 1900 wurden in Frankreich 21,3 Neugeborene pro 1000 gezählt, während es in Deutschland 35,6 waren. 1910 waren es 19,6 zu 29,8, 1930: 18,0 zu 17,6. Zahlen bei Tenfelde, Demographische Aspekte, S. 17f.; vgl. Dupâquier u. a., Histoire, Bd. 3, S. 353.

110 Vgl. Peukert, Alltagsleben, S. 145ff.; Kater, Generationskonflikt, S. 217-243; Jamin, Zwischen den Klassen.

111 Rougemont leitete als 24jähriger die literarische Reihe des Verlages Je sers; Daniel-Rops veröffentlichte seine Essaysammlung Notre inquiétude mit 25 Jahren, Maulnier seinen Essai La crise est dans l'bomme mit 23; Dandieu arbeitete bereits als Mittzwanziger zusammen mit Georges Bataille als Bibliothekar an der Pariser Nationalbibliothek, Jean Jardin wurde mit 29 Jahren persönlicher Referent des Direktors der französischen Eisenbahngesellschaft, vgl. Balmand, Jeunes intellectuels, S. 54; Prévost, Rencontres, S. 13; Assouline, Eminence grise, S. 44.

112 Berstein, La ligue, S. 61-111. 
mung waren Pazifismus und Militarismus nur relative Positionen, die je nach politischer Situation von unterschiedlichen Gruppierungen in unterschiedlichen Konstellationen zur Bezeichnung des jeweiligen Gegners gebraucht wurden ${ }^{113}$.

Mehr als alle anderen europäischen Länder hat Frankreich unter den Folgen des Krieges gelitten. Nur dort hatte die Zahl der Toten über zehn Prozent der aktiven männlichen Bevölkerung betragen; rund 1,4 Millionen französische Soldaten waren gefallen ${ }^{114}$. Dieser Krieg, der in besonders grausamen Materialschlachten, wie auf den Feldern von Verdun, überwiegend auf französischem Territorium geführt wurde, hatte sich in traumatischer Weise in die kollektive Erinnerung eingegraben ${ }^{115}$. Die Erinnerung daran prägte in besonderem Maße diejenigen Politiker und Intellektuellen, die im zweiten Nachkriegsjahrzehnt Macht und Einfluß erlangt hatten: Die dreißiger Jahre begannen nach einem Wort von Eugen Weber im August 1914116.

Auch die Nonkonformisten waren von dem Gedanken beherrscht, daß der Frieden ein ebenso bedrohtes wie bewahrenswertes Gut war. Anlaß zu Auseinandersetzungen gab jedoch die Art und Weise, mit der ein neuer Krieg wirksam verhindert werden konnte. Wie in den folgenden Kapiteln gezeigt werden wird, gab es innerhalb der jungen Intellektuellen deutliche Meinungsverschiedenheiten darüber, wie sie ihr Ziel erreichen konnten. Einig waren sie sich jedoch in der radikalen Opposition zum patriotisch-apolitischen Pazifismus, wie er insbesondere von den Frontkämpferverbänden propagiert wurde ${ }^{117}$.

Diese Differenzen wurden von den Nonkonformisten zum Generationskonflikt stilisiert. Im Bewußtsein der jungen Intellektuellen bildete die Teilnahme am Krieg das entscheidende Kriterium zur Abgrenzung zweier Generationen. In dem Maße, in dem die Veteranen das Fronterlebnis zu einem gemeinschaftsstiftenden Initiationsritus stilisierten und die Erinnerung daran in kultischer Form zelebrierten ${ }^{118}$, wurde den nachfolgenden Altersklassen der Ausschluß von dieser "Weihe“ als Defizit vermittelt. Wenn Antoine Prost betont, daß der aufopferungsvolle Einsatz der Frontkämpfer für die Verteidigung ihres Landes ihnen von den nachfolgenden Generationen Hochachtung und Respekt eintrug, so mag das einem Wunschbild entsprechen, aber nicht der Realität ${ }^{119}$. Die Frontkämpfergeneration bildete im Gegenteil geradezu das Feindbild der nonkonformistischen Generation. Die jungen Intellektuellen kehrten den Mythos in sein Gegenteil

113 Vgl. Vaïsse, Pazifismus, S. 590-616; Becker, La Première Guerre mondiale, S. 505-547; Ingram, Politics; Zum Pazifismus der Frontkämpfer Prost, Anciens combattants, Bd. 3, S. 78ff. Vgl. Wirsching, Nationale Geschichte, S. 180ff.

114 Vgl. dazu die Berechnungen bei Prost, Anciens combattants, Bd. 2, S. 2ff. und Weber, Hollow Years, S. 11.

115 Diese erfahrungsgeschichtliche Seite des Weltkrieges ist in den siebziger Jahren vor allem von französischer Seite zum Thema der Historiographie gemacht worden, vgl. den Forschungsüberblick bei Wirsching, Nationale Geschichte, S. 175-185. Dazu zählt insbesondere auch das oben zitierte dreibändige Werk von Prost, Anciens combattants.

116 Weber, Hollow Years, S. 11. Brunschwig stellt fest, daß im Unterschied zu Deutschland ein Generationswechsel in Frankreich erst in den dreißiger Jahren stattgefunden hat, vgl. Brunschwig, Die historischen Generationen, S. 373-385. Dieser Ansatz wird relativiert, aber nicht entkräftet bei Pinol, 1919-1958, S. 296ff., 310.

117 Vgl. Prost, Anciens combattants, Bd. 3, S. $98 \mathrm{ff}$.

${ }_{118} \mathrm{Zu}$ den Kultformen der Frontkämpfer siehe Prost, Anciens combattants, Bd. 3, S. $35 \mathrm{ff}$.

119 Prost, Jeunesse et société, S. 38. 
um. Sie waren beherrscht von der Vorstellung, in einem Land zu leben, das durch den Krieg bedrohlich geschwächt war und das dringend einer moralischen Erneuerung bedürfe ${ }^{120}$. Die großen Lücken, die der Krieg hinterlassen hatte, prägten die heranwachsende Generation in entscheidendem Maße. Die Verluste wurden in Frankreich als besonders bedrohlich empfunden, weil das Land ohnehin eine sinkende Geburtenrate aufwies. Angesichts des geburtenstarken und bevölkerungsreichen Nachbarn Deutschland steigerte dies den Eindruck des Niedergangs und der Unterlegenheit ${ }^{121}$.

Mit dem Thema des Generationskonfliktes begann die Abrechnung mit dem Nachkriegsjahrzehnt, den Jahren der Stabilisierung und der scheinbaren Ruhe, die nun als Jahre der Illusion erschienen. Die Kritik entzündete sich an dem Frontkämpfer-Pazifismus als einer vorherrschenden Geistesströmung der zwanziger Jahre. Im Jahr 1938 veröffentlichte der Ordre Nouveau-Mitarbeiter Xavier de Lignac seine Untersuchung über die Einstellung der französischen Jugend mit dem Titel La France attend sa jeunesse. Er konstatierte eine ausgesprochene Feindschaft zu den großen idealistischen Hoffnungen, von der die Generation ihrer Väter beseelt war, eine Skepsis gegenüber allen Utopien, eine Abneigung insbesondere gegen den Liberalismus, der von einem neuen, kämpferischen Realismus abgelöst werden müsse. Interessant ist in diesem Zusammenhang vor allem seine Definition von Jugend. Die Altersspanne faßte er sehr großzügig: sie reichte von den 18- bis 33jährigen ${ }^{122}$. Diese hohe Altersgrenze ergab sich in direkter Abgrenzung von der Frontkämpfergeneration: Zu den Jugendlichen zählten alle diejenigen, die nicht mehr einberufen worden waren ${ }^{123}$.

Seit dem Beginn der dreißiger Jahre mehrten sich die Diagnosen eines Wendepunktes, mit dem die Nachkriegszeit endgültig für abgeschlossen erklärt wurde ${ }^{124}$. Dies gab den Nonkonformisten die Gelegenheit, mit dem Thema des Generationskonfliktes an die Öffentlichkeit zu treten. Bei der Suche nach den Vorbildern seiner Altersgruppe stieß Jean-Pierre Maxence wiederum auf die große Zäsur des Weltkrieges. Er kam zu dem Ergebnis, daß diese entweder gefallen waren, wie Charles Péguy, oder den Krieg gedanklich nicht überwunden hatten, wie Charles Maurras und Maurice Barrès ${ }^{125}$. Diese Sichtweise bestätigte Daniel-Rops. Für ihn war das Lebensgefühl seiner Generation durch das vollständige Fehlen von unmittelbaren Vorbildern geprägt: „Wenn sich ein oft deutlicher Bruch zwischen zwei unmittelbar benachbarten Generationen abzeichnet, liegt der eigentliche Grund dafür in dieser Enttäuschung: wir, die wir in unserer Kindheit keine Vorbilder hatten, erwarteten unbewußt viel von den Älteren, die von der Front zurückkehrten. Wir erwarteten von ihnen schließlich die Erfüllung dieses Bedürfnisses nach Zuneigung, Unterwerfung, Vertrauen, das jeden Heranwachsenden nährt. Kein Fürsprecher ist in ihrem Namen zu uns gekommen." 126

120 Vgl. Winock, Esprit, S. 15f.; Balmand, Les jeunes intellectuels, S. 51 ff.; Sirinelli, Khâgneux, S. 43. 121 Vgl. Dupâquier u. a., Histoire, Bd. 4, S. 78.

122 Damit schloß sich der Autor, Jahrgang 1909, mit ein.

${ }^{123}$ Lignac, La France attend sa jeunesse, S. XV.

124 Vgl. Brasillach, La fin de l'après-guerre, in: Candide, H. 389 - H. 393, 1931. Unter anderem beteiligten sich an dieser Untersuchung Thierry Maulnier, Jean-Pierre Maxence und Daniel-Rops.

125 Maxence, Une génération sans maîtres?, in: RF, H. 6, 1932, S. 878-882.

126 Daniel-Rops, Années tournantes, S. 191. 
Dieses Bedauern über den geistigen Waisenstatus war zugleich ein schwerer Vorwurf an die Adresse der Frontkämpfergeneration. Denn Daniel-Rops ging davon aus, daß die Erfahrung einer solchen Extremsituation, das Ausbrechen aus bürgerlicher Enge, die Leiden und Opfer, der tägliche Einsatz des Lebens und die Allgegenwart des Todes, die Persönlichkeit in besonderer Weise prägen mußte. Dies war seiner Ansicht nach nicht der Fall, kein Veteran taugte zum Führer der Jugend. Der Krieg hatte in seinen Augen nur eine große Lücke hinterlassen. Von hier aus ist es nicht weit zu der Ansicht, daß der Krieg sogar zu einer Art Negativauslese geführt habe. Wenn Thierry Maulnier betonte, die Besten des Landes seien im Kampf für das Vaterland gefallen, so muß man nicht sonderlich spitzfindig sein, um dies als Affront gegen die Überlebenden zu begreifen. Die Sinnlosigkeit des Krieges, wie sie von den Frontkämpfern immer wieder betont wurde, ist in diesen Äußerungen noch um eine Dimension gesteigert: Frankreichs Zukunft war im Krieg begraben worden, die notwendige Erneuerung hatte nicht stattgefunden. Die Nachkriegsgeneration, so forderte Maulnier, mußte nun den Impuls aufgreifen und das Werk der Gefallenen vollenden ${ }^{127}$.

Die Kritik an den Frontkämpfern entzündete sich nicht an deren Friedenssehnsucht, sondern an der mangelnden Radikalität, mit der sie ihre Ziele verfolgten. In der Auseinandersetzung kamen die fundamentalen Erschütterungen des Weltkrieges an die Oberfläche. Eine dauerhafte Friedensordnung konnte aus der Sicht der Nonkonformisten nur durch eine radikale Abkehr von den Grundlagen des liberal-kapitalistischen Systems verwirklicht werden. Die Frontkämpfergeneration aber war aus dieser Perspektive zu stark in den Ideen verwurzelt, die den Krieg überhaupt erst ermöglicht hatten.

Jede Beurteilung der Folgen des Weltkrieges muß der ebenso einfachen wie grundlegenden Tatsache Rechnung tragen, daß Deutschland als Verlierer, Frankreich als Sieger aus dem Krieg hervorgegangen ist. Das Fronterlebnis konnte erst durch die Niederlage zum Mythos werden. Mit der Dolchstoßlegende wurde die Verantwortung für die Niederlage den republikanischen Kräften aufgebürdet: sie seien dem deutschen Militär in den Rücken gefallen und trügen die alleinige Schuld an der verfrühten Kapitulation und den Friedensbedingungen, wie sie im Versailler „Diktat“ festgelegt worden waren. Soweit gehörte die Dolchstoßlegende zum ideologischen Inventar der Rechten und begründete die Feindschaft zu dem von den Siegermächten "oktroyierten“ liberalen System. In den Kreisen der Konservativen Revolution aber wurde diese Rechtfertigungsstrategie mit einem neuen Sinn unterlegt. Die Niederlage wurde zur historischen Notwendigkeit. Erst aus ihr erwachse ein besseres, "geheimes" Deutschland, das in den "Stahlgewittern" des Krieges geboren war. Sie begründete den Mythos von der Nation, deren Wertesystem dem Liberalismus westlicher Prägung diametral entgegengesetzt war. Kurzum: Die Konservative Revolution war eine Verliererideologie ${ }^{128}$.

Gerade aufgrund dieser spezifisch politischen Prägung des Fronterlebnisses wird deutlich, warum sich eine vergleichbare Interpretation des Kriegserlebnisses in Deutschland und Frankreich nicht entwickeln konnte - zumindest nicht zu diesem Zeitpunkt. An dieser Stelle möchte ich eine Hypothese formulieren: Auch der Nonkonformismus

127 Maulnier, Les conservateurs, Combat, H. 5, 1936, S. 67f. Weitere Beispiele für die kritische Auseinandersetzung mit den Frontkämpfern bei Touchard, Esprit, S. $97 f$.

${ }^{128}$ Mohler, Konservative Revolution, Bd. 1, S. 37f.; Kondylis, Konservativismus, S. $470 \mathrm{ff}$. 
war eine Ideologie, die in der Vorstellung vom Niedergang der eigenen Nation wurzelte. Er entstand zu einem Zeitpunkt, als die französische Hegemonie auf dem Kontinent in Frage gestellt wurde, als Deutschland wieder zur Großmacht aufstieg, als schließlich auch die innere Schwäche der Dritten Republik deutlich spürbar wurde. Auch er wurzelte in der Vorstellung von einem „anderen“, verjüngten Frankreich, das sich gegen das republikanische System auflehnte. Auch die Nonkonformisten traten mit dem Bewußtsein an, eine historische Mission zu erfüllen, indem sie den Liberalismus bekämpften. Das heißt: Der Ansatzpunkt für einen Vergleich ist nicht in den konkreten inhaltlichen Forderungen, sondern in den Argumentationsstrukturen zu suchen. Sie werden erst sichtbar, wenn der Standort der Gruppierungen innerhalb des jeweiligen nationalen Rahmens bestimmt ist.

\section{Intellektuellenkultur}

In seiner politischen Semantik war der Begriff des Intellektuellen durch die Dreyfus-Affäre geprägt worden und hat die Argumentationsmuster mehrerer Generationen von Intellektuellen bestimmt. Ursprünglich als Schimpfwort auf die Parteigänger des Hauptmanns gemünzt, wurde es von diesen aufgegriffen und positiv umgewertet. Daher haben sich die Bedeutungen des Wortes in einer Reihe antagonistischer Begriffspaare entwikkelt, die je nach dem politischen Standort des Benutzers akzentuiert werden konnten. Zwei konkurrierende Wertvorstellungen standen sich gegenüber: Die Dreyfusards würdigten den Intellektuellen als einen Verteidiger der universalistischen Prinzipien der Menschen- und Bürgerrechte, deren Gegner hingegen erklärten ihn zum entwurzelten Rationalisten und Verräter der Nation. Für die einen ein idealistischer Verfechter von Wahrheit und Vernunft, war er für die anderen ein realitätsferner Phantast, der die Prägung des Menschen durch Herkunft und Abstammung leugnete. Dem radikalen Laizismus der Dreyfusards standen die ebenso radikalen Verfechter des politischen Katholizismus gegenüber ${ }^{129}$.

In paradigmatischer Weise, so die These von Michel Winock, standen damit die Konfliktkonstellationen über mehr als ein halbes Jahrhundert hinaus fest. Diese These impliziert, daß in der Dreyfus-Affäre mit der Krise zugleich die Mechanismen zu ihrer Bewältigung eingeübt worden sind und sich Frankreichs politische Kultur seither als relativ resistent gegenüber allen Angriffen auf die Republik erwiesen habe ${ }^{130}$. Inwieweit dies für die dreißiger Jahre zutrifft, wird im Kapitel „Antisemitismus und Antiliberalismus“ überprüft.

Die Auseinandersetzung zwischen Dreyfusards und Antidreyfusards wurde in den Medien ausgetragen; die Parteigänger beider Lager versuchten, durch ihre Intervention die Meinungsbildung zu steuern und auf diese Weise den politischen Entscheidungsprozeß zu beeinflussen. Vor allem aber traten die Intellektuellen im Verlauf der Affäre erstmals durch eine kollektive Intervention hervor. Insofern markierte die Affäre die Ge-

129 Ory/Sirinelli, Les Intellectuels, S. 13ff. Charle, Naissance, S. 54ff.; Bauman, Unerwiderte Liebe, S. $183 \mathrm{ff}$.

130 Winock, Les Affaires Dreyfus, S. 19-37. 
burtsstunde des "Intellektuellen“ nicht nur in seiner spezifischen Semantik, sondern auch einer Praxis, die in Frankreich die Intellektuellenkultur maßgeblich bestimmte. Stand der Beginn der Affäre mit dem "J'accuse" von Emile Zola noch in der Tradition des Einzelkämpfers, der die Autorität seiner Persönlichkeit einsetzte, so etablierten sich in der Folge die Formen der kollektiven Intervention: der Petition, die direkt an einen Entscheidungsträger gerichtet war, und des veröffentlichten Manifestes. Ihre Bedeutung wurde durch Anzahl und Rang der unterzeichnenden Intellektuellen und gegebenenfalls durch den Ort der Veröffentlichung bestimmt ${ }^{131}$.

Eine ausgeprägte und einflußreiche Presselandschaft bildete die Voraussetzung für die Entfaltung der Intellektuellenkultur. Entscheidend aber war die Expansion des Bildungswesens seit dem Ende des 19. Jahrhunderts. Mit dessen Reform etablierte sich ein neuer Zugang zur Elite der Intellektuellen: Ein akademischer Abschluß war bis dahin keineswegs eine notwendige Voraussetzung, der bomme de lettres im 19. Jahrhundert hatte verhältnismäßig selten eine Universität besucht. In der Folge der Reform gewann jedoch der Anteil der Akademiker rasch an Gewicht. Professoren und Lehrer setzten sich als die maßgeblichen Berufsgruppen durch, der Status des Intellektuellen wurde immer mehr durch Ausbildung und Beruf definiert. Da die Zahl der einflußreichen politischen Beraterstellen begrenzt blieb, mußte sich die Masse der Akademiker andere Einflußmöglichkeiten suchen. Sie verschaffte sich im expandierenden Zeitschriftenmarkt Gehör. Die Praxis der öffentlichen Intervention konstituierte somit eine Gruppe, die nach Ansicht von Christophe Charle erfolgreich mit den traditionellen bürgerlichen $\mathrm{Be}-$ amten- und Beraterpositionen konkurrierte, die Pantouflage bekämpfte und meritokratische Prinzipien durchsetzte ${ }^{132}$. Die einzigartige Konzentration von Hochschulen, Medien und politischer Macht in Paris stärkte die Position der Intellektuellen im Ringen mit den traditionellen republikanischen Eliten. Sie förderte zugleich die personellen Verflechtungen zwischen Schulen, Hochschulen, Zeitschriften und Politik ${ }^{133}$.

Der Gebrauch des durch die Dreyfus-Affäre geprägten politischen Kampfbegriffes für wissenschaftliche Zwecke ist problematisch. Um der Gefahr einer Parteinahme zu entgehen, wird im folgenden von den inhaltlichen Positionen abstrahiert. Eine solche Verwendungsweise entsprach auch in der Zwischenkriegszeit in zunehmendem Maße der gängigen Praxis. Der „Intellektuelle" entwickelte eine solche Integrationskraft, daß er sich seit Mitte der zwanziger Jahre auch bei der extremen Rechten als Selbstbezeichnung einbürgerte ${ }^{134}$. Gegen die weitere Eingrenzung des Begriffes durch sozioprofessio-

131 Sirinelli, Intellectuels et passions françaises, S. $21 \mathrm{ff}$.

132 Charle, Naissance, S. 82ff., 229ff.; vgl. Sirinelli, Intellectuels et passions françaises, S. $57 \mathrm{ff} ., 83 \mathrm{ff}$.

133 Ein Bindeglied zwischen Hochschulen und Zeitschriften war der Philosoph Alain, eigentlich Emile Chartier; vgl. Sirinelli, Alain, S. 272-283. Auf die enge Verflechtung von Hochschulen und Politik rekurriert der Topos der „Republik der Professoren“ (Albert Thibaudet). Er gründete sich auf die relativ hohe Zahl von Professoren insbesondere aus der ENS in der Regierung des Linkskartells 1924-1926. Aber er täuscht insofern, als die Intellektuellen weder zu diesem Zeitpunkt noch in den dreißiger Jahren während der Volksfront eine Mehrheit unter den Abgeordneten stellten. Im April/Mai 1936 waren es $10 \%$, vgl. Sirinelli, Intellectuels et passions françaises, S. 84; Thibaudet, La République des professeurs. Etwas schematisch konstatiert Debray das Überschneiden des cycle universitaire (1880-1930) mit dem cycle éditorial (1920-1960) in den zwanziger Jahren, vgl. Debray, Le Pouvoir intellectuel, S. 49ff., $73 \mathrm{ff}$.

134 Sirinelli, Intellectuels et passions françaises, S. 68ff. 
nelle Kriterien sprechen vor allem zwei Gründe: Erstens gab es auch nach der Bildungsreform keinen verbindlichen Weg, um als Intellektueller anerkannt zu werden, und zweitens charakterisierte den Intellektuellen gerade das Überschreiten seines fachspezifischen Horizontes. Entscheidend ist vielmehr die Form seines Engagements: Er intervenierte in politischen Fragen mit moralischen Argumenten. Er begründete seinen Standpunkt mit dem Verweis auf etablierte Normen- und Wertesysteme (Menschenrechte, Universalismus, Nationalismus, Katholizismus). Je nach seinem Selbstverständnis als "Priester" oder „Prophet" sah er seine Aufgabe darin, diese zu bewahren oder sie $\mathrm{zu}$ verändern ${ }^{135}$.

Wie Diez Bering gezeigt hat, wurde die in der Dreyfus-Affäre entwickelte Semantik des Intellektuellenbegriffes auch in Deutschland rezipiert. Allerdings läßt sich die Entwicklung dort eher als "Geschichte eines Schimpfwortes" nachzeichnen; positive Anknüpfungen an den Dreyfusard fehlten weitgehend - auch in der Phase der Weimarer Republik ${ }^{136}$. Selbst in den Kreisen bürgerlicher Humanisten wie Alfred Döblin, Ernst Robert Curtius und Hermann Keyserling überwogen die negativen Konnotationen. Einen entschiedenen Verfechter hatte der Begriff nur in Heinrich Mann gefunden, der in seinem Zola-Essay dem Repräsentanten des republikanischen Intellektuellen ein Denkmal gesetzt hatte ${ }^{137}$. Wenn sich der "Intellektuelle“ in Deutschland nicht zu einem positiven Integrationsbegriff entwickeln konnte, so bedeutet dies natürlich nicht, daß es keine Intellektuellenkultur gab. Gerade die zwanziger Jahre waren geprägt von einem florierenden Zeitschriftenmarkt, in dem sich eine bis dahin unbekannte Meinungsvielfalt entwickelte. Es fehlten allerdings die entschiedenen Verfechter des demokratischen Rechtsstaates, wie sie in Frankreich auf der Seite des Hauptmanns Dreyfus gestanden hatten. Eine Streitkultur, die dem Verteidiger republikanischer Ideale einen vergleichbaren symbolischen Rang zumaß, hatte sich in Deutschland nicht entwickelt ${ }^{138}$.

In Frankreich lieferten die Aktivitäten der Intellektuellen einen zuverlässigen Indikator für die Intensität der politischen Auseinandersetzungen. Einen Höhepunkt erreichten sie in den dreißiger Jahren, die auch als die "Zeit der Manifeste" bezeichnet werden. $\mathrm{Zu}$ keiner anderen Zeit häuften sich die Anlässe zur Intervention so wie in jenen Jahren: der Pazifismus in der Tradition Briands, der Abessinienkrieg, der spanische Bürgerkrieg usw. ${ }^{139}$. Zugleich wurde eine außerordentlich große Zahl neuer Zeitschriften gegründet, in denen meist jüngere Intellektuelle ihre Ideen verbreiteten. Mit der Expansion des Marktes wandelte sich auch der Umgangston: der Typus des militanten Kämpfers trat auf den Plan - ein deutliches Zeichen eines politischen Klimawechsels ${ }^{140}$, aber mögli-

135 Vgl. Ory/Sirinelli, Les Intellectuels en France, S. 10; Lepsius, Kritik, S. 270-283.

136 Bering, Die Intellektuellen.

137 Damit hatte er den Zorn seines Bruders auf sich gezogen, der sich mit dem Verdikt des „Zivilisationsliteraten" in den Betrachtungen eines Unpolitischen rächte. Vgl. allgemein Bering, Die Intellektuellen, S. $263 \mathrm{ff}$.

138 Vgl. Bering, Die Intellektuellen, S. 308ff. Gangl, Einleitung zu Intellektuellendiskurse, S. 9-11; Eßbach, Einleitung zu Intellektuellendiskurse, S. 15-17; vgl. Ringer, Fields, S. 70ff., und ders., Die Gelehrten, S. 15f.; ders., Rezension von Christian Simon, S. 103f.; ähnlich Charle, Naissance, S. 230.

139 Sirinelli, Intellectuels et passions françaises, S. 83 ff.; Racine-Furlaud, Bataille, S. 223-238.

140 Vgl. Picciola, La vie des revues, S. $139 \mathrm{ff}$. 
cherweise auch eine Reaktion auf den härteren Verdrängungswettbewerb in der Zeitschriftenbranche.

In besonderer Weise haben die Nonkonformisten dazu beigetragen, das Bild eines neuen, engagierten Intellektuellen zu prägen. Ihr Standort im Koordinatensystem der französischen Intellektuellenkultur läßt sich exemplarisch an ihrer Haltung zu zwei Persönlichkeiten bestimmen: Charles Péguy und Julien Benda. Die Verehrung für den ersten und die Kritik an letzterem charakterisieren den gemeinsamen Ausgangspunkt der jungen Intellektuellen. Benda war 1927 mit seinem Werk La trabison des clercs als kompromißloser Ankläger der Intellektuellen, die sich von politischen Leidenschaften hinreißen lassen, aufgetreten. Seine Kritik richtete sich gegen die zunehmende Politisierung der Öffentlichkeit durch diejenigen, die nach seiner Ansicht eigentlich die Verteidiger der "reinen Wahrheit“ sein sollten. Immer mehr Intellektuelle machten sich Benda zufolge aus Furcht oder aus Bequemlichkeit zu Fürsprechern von Parteiinteressen. Statt sich auf die allgemeinen und abstrakten Werte der Menschlichkeit, auf Freiheit, Recht und Vernunft, zu berufen, ließen sie sich von Stimmungen und Vorurteilen leiten. Besonders hart ging Benda mit dem "clerc nationaliste“ ins Gericht, der die Nation über die Freiheit des einzelnen und die Macht über das Recht stellte. Ausgehend vom deutschen Idealismus, über Schlegel, Fichte und Schelling, war dieses Gedankengut im Zuge der Dreyfus-Affäre auch in Frankreich eingedrungen und hatte Benda zufolge clercs wie Barrès, Maurras und Massis in die Niederungen der politischen Arena getrieben ${ }^{141}$.

Mit diesem mahnenden Plädoyer für den Intellektuellen, der sich von der Welt der Politik fernhält (clerc désintéressé), hatte sich Benda zum Lieblingsfeind der Nonkonformisten gemacht. In ihren Augen repräsentierte er den Typus des bürgerlichen Intellektuellen, wie ihn die Dreyfus-Affäre hervorgebracht hatte. Die Jeune Droite, die zu ihren Vorbildern die von Benda attackierten nationalistischen Intellektuellen zählte, griff in ihrer Verteidigung auf die Stereotype der Antidreyfusards zurück. Für Jean de Fabrègues war Bendas Position nichts anderes als der „ewige Irrtum“ des Idealismus, der durch den Rückzug in die abstrakte Welt der Ideen den Kontakt zur Realität verloren habe. Dem gläubigen Katholiken Benda warf er vor, sich mit dieser Haltung vom Christentum entfernt zu haben ${ }^{142}$. Nach Ansicht von Fabrègues bedeutete das Bekenntnis zum Katholizismus die Verpflichtung zum politischen Engagement, und zwar gegen alle Prinzipien, „die dem christlichen Menschenbild diametral engegengesetzt waren: Materialismus, Determinismus und die Taten der, Gottlosen “" ${ }^{143}$. Im Unterschied zu Benda waren für ihn Katholizismus und Republikanismus unvereinbar. Eine liberal-demokratische Ordnung widersprach seiner Auffassung nach fundamental der katholischen Lehre. Die "natürlichen“, gewachsenen Autoritäten, „Familie, Beruf und Vaterland“, sah Fabrègues bedroht durch die republikanischen Ideale, wie sie Benda propagierte ${ }^{144}$. In die gleiche Richtung zielte die Kritik Thierry Maulniers, jedoch fehlten bei ihm die Anklänge eines politischen Katholizismus. Er attackierte das „rein abstrakte Denken“ der Schriftsteller des Nachkriegsjahrzehnts und betonte gerade angesichts der Krise die

\footnotetext{
${ }^{141}$ Benda, La trahison des clercs, S. $55 f$.

142 Fabrègues, Julien Benda, L'Ordre et Dieu, in: Réaction, H. 5, 1931, S. 21-24, hier S. 24.

143 Fabrègues, Nécessité de s'engager, in: Revue du XXe siècle, H. 1, 1934, S. 38-40, Zitat S. 38.

144 Fabrègues, Capital et Capitalisme, in: Réaction, H. 10, 1932, S. 1-6, Zitat S. 5.
} 
moralische Pflicht zum politischen Engagement: „[...] die Literatur läßt sich kaum noch von der militanten Politik trennen". 145

Ähnliche Attacken auf den Repräsentanten bürgerlich-humanistischer Werte kamen vom Ordre Nouveau. Der „Intellektuelle, der keinen Verrat übt“ ${ }^{146}$, wurde zum Inbegriff des weltfremden Idealisten, der seine Zuflucht im längst vergangenen System des aufklärerischen Rationalismus suchte. Für Aron und Dandieu war der außerordentliche Erfolg eines Benda geradezu symptomatisch für die gegenwärtige Situation Frankreichs. Sie kehrten seinen Vorwurf des Verrats um und bezichtigten gerade die Verteidiger von Vernunft, Wahrheit und Menschenrechten, am Niedergang des eigenen Landes schuld zu sein: „Die Flucht vor dem Konkreten, das ist der schreckliche Verrat der Intellektuellen, dessen idealistische Schwäche Frankreich und die Welt bedroht. ${ }^{147}$ An seine Stelle trat der engagierte Intellektuelle (clerc engagé), der sich seiner politischen Verantwortung bewußt war und seine Ideen in die Tat umsetzte. Die von den Nonkonformisten diagnostizierte Krise erforderte radikale Lösungen: „Dem Realismus, der Gewalt, der Autorität, dem Risiko, der Originalität, der Vorstellungskraft, dem Stil wieder Wert verleihen - Tugenden, die durch den bürgerlichen Pseudoliberalismus aufgeweicht oder pervertiert wurden. " 148

Ein Vorbild des engagierten Intellektuellen, der die Verstrickung in die Politik nicht scheute, hatten die Nonkonformisten in dem Schriftsteller Péguy gefunden. Die Vermutung liegt nahe, daß Péguy die Verehrung, die er in den Kreisen der nonkonformistischen Generation genoß, zum Teil seinem frühen Tod an der Front 1914 verdankte. Bereits zu Beginn der dreißiger Jahre setzte eine intensive Beschäftigung mit dem Schriftsteller ein. Jean-Pierre Maxence veröffentlichte 1931 einen Essay mit dem Titel Péguy et l'événement, im selben Jahr erschien La pensée de Charles Péguy, verfaßt von den Gründern des Esprit-Kreises Georges Izard und Emmanuel Mounier in Zusammenarbeit mit Marcel Péguy, dem Sohn des Schriftstellers, und schließlich folgte 1933 das Werk von Daniel-Rops ${ }^{149}$. Deutlich später, während des Zweiten Weltkrieges, verfaßte auch Alexandre Marc ein Werk über Péguy (1941). Dies war das Resultat einer langjährigen Beschäftigung mit dem Autor, dessen Werk er bereits Ende der zwanziger Jahre entdeck$\mathrm{te}^{150}$. Über die gemeinsame Sympathie für Péguy ergaben sich auch Kontakte zwischen dem Esprit-Kreis und der Jeune Droite. Auf den Sitzungen der von Charles Péguy ge-

145 Maulnier, La crise est dans l'homme, S. 15.

146 Daniel-Rops/Rougemont, Spirituel d'abord, in: Ordre Nouveau (ON), H. 3, 1933, S. 13-17, Zitat S. 16.

147 Aron/Dandieu, Décadence de la nation française, S. 73.

${ }^{148}$ Rougemont, Penser avec les mains, in: Union pour la vérité, H. 5-6, 1937, S. 241-244, Zitat S. 243.

${ }^{149}$ Maxence, Péguy et l'événement, in: Cahiers de la Quinzaine, H. 21, 1931, S. 9-35; Mounier/ Izard/M. Péguy, La pensée de Charles Péguy; Daniel-Rops, Péguy.

150 Dies bestätigte mir Marc in einem Gespräch am 4. 12. 1994; vgl. auch ders., Tradition renouée, in: ON, H. 8, 1934, S. 1-6; demnächst dazu die Arbeit von Baird über Marc, die sich unter anderem auf die Auswertung seines Tagebuches stützt. Mehrere Mitarbeiter vom Ordre Nouveau, Dandieu, Aron, Ollivier, verkehrten zudem im Salon von Daniel Halévy, der ein enger Freund von Péguy war, vgl. Aron, Charles de Gaulle, S. 40ff. 
gründeten und von seinem Sohn Marcel wiederaufgelegten Cabiers de la Quinzaine trafen sich unter anderem Mounier, Izard, Fabrègues und Maxence ${ }^{151}$.

Als Kritiker der reinen Vernunft und Anwalt des Antiintellektualismus verkörperte Péguy den Typus des Anti-Benda ${ }^{152}$. Er eignete sich vor allem deshalb als Identifikationsfigur, weil er - inspiriert von Bergsonscher Lebensphilosophie - das Charisma und die Dynamik der Jugend ausstrahlte. Er verzichtete auf den Standpunkt des überlegenen Beobachters, beanspruchte das Recht auf Irrtum und engagierte sich in verschiedenen politischen Lagern. Als Sozialist setzte er sich in der Dreyfus-Affäre für die Rechte des Hauptmanns ein. Unter dem Eindruck der Marokkokrise orientierte er sich zunehmend an nationalistischen Positionen und avancierte zu einer Leitfigur der neothomistischen Erneuerungsbewegung, dem Renouveau catholique. Mit der Hinwendung zu einem mystischen Traditionalismus geriet er immer deutlicher in Gegensatz zu den Verfechtern republikanischer Ideale ${ }^{153}$. Péguys katholische Zivilisationskritik und seine charismatische Persönlichkeit zogen die Nonkonformisten in den Bann: Sie verehrten ihn als Führer und Propheten, sie suchten bei ihm die Antworten auf die Probleme ihrer eigenen Epoche: „Es scheint, daß zwischen unserer Situation und der, in der er gelebt hat, äußerst viele Gemeinsamkeiten bestehen! Ist er nicht eines der besten, vielleicht eines der letzten Beispiele für einen Schriftsteller, der Mensch geblieben ist, der nicht versucht, eine entwurzelte Mystik, sondern den Menschen, der er ist, und die Menschen, denen er begegnet, und die Ereignisse, die seine tägliche Aufgabe bestimmen, zu durchdringen. ${ }^{1} 154$

Sichtbarer Ausdruck dieses neuen Verständnisses von intellektuellem Engagement waren die zahlreichen Zeitschriften, die von den Nonkonformisten gegründet wurden: Les Cabiers (1928-1931) von Maxence, Réaction (1930-1932) von Fabrègues, Plans (1931-1933) von Lamour, Mouvements (1932-1933) von Lapie, Esprit (1932-1941) von Mounier, Ordre Nouveau (1933-1937/38) von Aron, Marc u. a., Homme nouveau (1934-1937/38) von Roditi, Lutte des Jeunes (1934) von Bertrand de Jouvenel, Revue du siècle (1933-1934), Revue du XXe siècle (1934-1935) von Fabrègues, Combat (19361939) von Fabrègues und Maulnier. Die Auflagen dieser Zeitschriften waren gering, sie reichten von 1000 bis zu 5000 Exemplaren. Eine wesentlich größere Breitenwirkung erreichten die Nonkonformisten allerdings über die Mitarbeit in benachbarten Organen und durch die Veröffentlichung ihrer Werke, deren Auflagen mitunter dreißigtausend Exemplare überstiegen ${ }^{155}$.

Die Redaktionsstuben fungierten als Kommunikationszentren und Versammlungsorte. Sie garantierten den Zusammenhalt der Kreise, ohne daß es einer festen Organisa-

151 Vgl. Briefe Jean Chauvys an Denis de Rougemont vom 11.2. [1933] und 11. 3. [1933], Archives Denis de Rougemont, Neuchâtel, Correspondance.

152 Balmand, L'anti-intellectualisme, S. 35ff.; vgl. Winock, Esprit, S. 21.

153 Cohen, Piety and Politics, S. 250ff.; Leroy, Péguy.

${ }^{154}$ Maxence, Péguy, S. 34; vgl. Daniel-Rops, Péguy, S. 25f.; Mounier, Vorwort zu La pensée de Charles Péguy, Wiederabdruck in Mounier, Euvres, Bd. 1, S.13-15; Fabrègues, Péguy, Prophète et Guide, Revue du siècle, H. 6, 1933, S. 55-59.

155 Eléments de notre destin (1934) von Daniel-Rops erreichte eine Auflage von 35000 Exemplaren, La Révolution nécessaire (1933) von Aron und Dandieu wurde siebenmal aufgelegt, Jeune Europe von Dupuis und Marc wurde von der Académie française ausgezeichnet; Lipiansky, Ordre Nouveau, S. 90. Für seinen Nietzsche (1933) erhielt Maulnier den Grand prix de la critique. 
tion bedurfte. Finanziell waren die Zeitschriften häufig ein Verlustunternehmen, im besten Fall brachte der Verkaufserlös die Produktionskosten wieder ein. Honorare wurden niemals gezahlt, eher mußten die Redakteure noch selbst Geld beisteuern. Die Arbeit verlangte also ein hohes $\mathrm{Ma} ß$ an Einsatz, zumal die Redakteure ihren Lebensunterhalt anderweitig verdienen mußten. Trotz dieser materiellen Schwierigkeiten garantierten die eigenen Zeitschriften die Unabhängigkeit von den Gesetzen des Marktes und damit des heftig bekämpften Kapitalismus. In einer Zeit, in der der Journalismus zunehmend professionalisiert und die Zeitung zu einem Massenmedium wurde, war diese Haltung der Ausdruck einer verweigerten Anpassung ${ }^{156}$. In dieser Organisationsform ähnelten die Nonkonformisten stark der Konservativen Revolution. Auch in Deutschland handelte es sich meist um kleine literarische Zirkel, elitäre Kreise, Redaktionen von Zeitschriften und Gefolgschaften einiger charismatischer Persönlichkeiten ${ }^{157}$.

Dennoch wäre es verfehlt, diese Gruppierungen beiderseits des Rheins als isolierte Intellektuellenzirkel zu betrachten. Die Konservativen Revolutionäre verfügten vielmehr über ein Netzwerk von persönlichen Verbindungen zu einflußreichen Vertretern von Industrie und Politik. Nur einige Beispiele seien hier genannt: Der Juniklub um Moeller van den Bruck besaß sehr gute Verbindungen zu Alfred Hugenberg, der die Gruppierung auch finanziell unterstützte ${ }^{158}$. Der Tatkreis stand in engem Kontakt zum Reichswehrminister Schleicher und unterstützte dessen Pläne einer "nationalen Volksfront ${ }^{\text {“159. }}$ Die Umstände des Aufstiegs von Carl Schmitt zum „Kronjuristen des Dritten Reiches“ sind in einer jüngst erschienenen Untersuchung rekonstruiert worden ${ }^{160}$. Einen Einblick in die zahlreichen Querverbindungen der Konservativen Revolution gibt der bibliographische Anhang in Mohlers Handbuch ${ }^{161}$. Diese Verflechtungen zwischen den Intellektuellenzirkeln und der Politik sind ein zentraler Bestandteil des Phänomens. Sie erklären auch, warum der Schwerpunkt der Konservativen Revolution in der Hauptstadt Berlin lag: hier war die Nähe zur Macht am größten.

Auch die Aktivitäten der Nonkonformisten beschränkten sich keineswegs auf die Publizistik. Sie waren vielmehr von dem Gedanken beherrscht, ihre Ideen auch in die Tat umzusetzen. Bei ihrer Suche nach Verbündeten knüpften sie Kontakte zu Unternehmerverbänden, Gewerkschaften, Ligen und politischen Gruppierungen. Diese zahlreichen Querverbindungen sind bisher weitgehend unbeachtet geblieben. Daher wird die Rekonstruktion dieser Beziehungen und des Kommunikationsnetzes in den folgenden Kapiteln eine wichtige Rolle spielen. Sie soll die Frage klären, wie weit der Einfluß der französischen Intellektuellen über den Rahmen ihrer Zeitschriften und Werke hinausging.

\footnotetext{
156 Vgl. Chevalley/Glady [Marc], La mort des partis, in: ON, H. 4, 1933, S. 19-27; Aron, L'écrivain et l'argent, in: Esprit, H. 13, 1933, S. 68-71.

157 Vgl. Mohler, Konservative Revolution, Bd. 1, S. $59 f$.

${ }_{158}$ Mohler, Konservative Revolution, Bd. 1, S. 60 f.

${ }^{159}$ Sontheimer, Tatkreis, S. 229ff.; Fritzsche, Politische Romantik, S. $277 \mathrm{ff}$.

160 Koenen, Der Fall Carl Schmitt.

${ }^{161}$ Mohler, Konservative Revolution, Bd. 1, S. $173 \mathrm{ff}$.
} 


\section{Zusammenfassung}

Bereits der Überblick über den zeitlichen Verlauf der Krisen zeigt die Problematik, einen Vergleich der beiden Phänomene in Deutschland und Frankreich auf die frühen dreißiger Jahre zu konzentrieren. In Deutschland geriete damit nur die Spätphase der Konservativen Revolution ins Blickfeld, während in Frankreich die eigentliche Welle des Protestes noch bevorstehen würde. Zu einer Zeit, als die Gruppierungen und Zirkel östlich des Rheins bereits die Fundamente der politischen Kultur der Weimarer Republik erschütterten, waren die Kreise westlich des Rheins erst im Aufbau begriffen. Somit erscheint es wenig sinnvoll, die Gruppierungen einander unmittelbar gegenüberzustellen.

Vielmehr lohnt es sich, Konservative Revolution und Nonkonformismus in ihren spezifischen Entstehungs- und Rahmenbedingungen näher zu betrachten. Die soziale $\mathrm{Zu}$ sammensetzung beider Kreise ähnelt sich in vielerlei Hinsicht. Die Protagonisten entstammten großteils derselben bürgerlichen Schicht. Unter den Nonkonformisten gab es - infolge des elitären Ausbildungssystems - eine besonders hohe Zahl von Angehörigen des Bildungsbürgertums und der freien Berufe.

In beiden Ländern gab die Großstadtkultur entscheidende Impulse für die Entstehung der Gruppierungen. Viele der Konservativen Revolutionäre und Nonkonformisten kamen erst zum Studium in die Metropolen. Hier hatten sie Gelegenheit, neue Kontakte zu knüpfen und mit Gleichgesinnten in Verbindung zu treten. Dies erklärt, warum die meisten Zirkel während und unmittelbar nach dem Studienjahren entstanden. Zudem waren gerade die Großstädte Brennpunkte der sozialen und politischen Konflikte, die in jenen Jahren kulminierten. Das Fehlen einer klaren Organisationsstruktur mit festen Regeln ist charakteristisch für die Gruppierungen beiderseits des Rheins. Es handelte sich in der Mehrzahl um informelle Zirkel, die sich häufig um einen Freundeskreis oder eine charismatische Persönlichkeit herum bildeten. Die Redaktionen kleinerer Zeitschriften wurden zu fruchtbaren Diskussionszentren sowohl der Konservativen Revolution als auch der Nonkonformisten.

Beiderseits des Rheins gehörten die Revolutionäre zur Minderheit derjenigen, die ein Studium, und zwar vorzugsweise im geisteswissenschaftlichen Bereich, absolviert hatten. Humanistische Bildungsideale waren das Standardrepertoire der bildungsbürgerlichen Sozialisation, die ein Großteil der Protagonisten durchlebte. Sie waren geprägt von dem Bewußtsein, mit dem Erwerb zweckfreien Wissens einem elitären Kreis anzugehören. Dahinter stand der mehr oder weniger deutlich artikulierte Anspruch, eine entsprechende Position im gesellschaftlichen Leben einzunehmen. Problematisch wurde dies in dem Moment, wo die Ausbildung nicht mehr einen entsprechenden Status im Berufsleben und damit in der Gesellschaft garantierte, oder ein einschneidendes Erlebnis wie der Weltkrieg eine Rückkehr in die bürgerliche Gesellschaft erschwerte. Dies war in Deutschland bei der Frontkämpfergeneration und der nachfolgenden sogenannten „überflüssigen Generation“ der Fall. Ihre Lebensentwürfe waren besonders häufig vom Scheitern bedroht. Dadurch bildeten sie ein gefährliches Protestpotential und den Nährboden für extremistische Bewegungen aller Richtungen. Besonders bedrohlich wurde die Situation durch die geburtenstarken Jahrgänge, die seit dem Ende der zwanziger Jahre auf den Arbeitsmarkt drängten. 
Anders in Frankreich. Die Nonkonformisten gehörten nahezu ausschließlich zur Generation derjenigen, die den Krieg nicht mehr an der Front hatten erleben müssen. Im Unterschied zu Deutschland gab es in dieser Altersklasse in Frankreich keinen Geburtenüberschuß. Der Kampf um Arbeit und Brot hatte für sie daher nicht dieselben existentiellen Ausmaße wie in Deutschland, auch wenn Frankreich Anfang der dreißiger Jahre in den Sog der Weltwirtschaftskrise gerissen wurde. Die soziale Not war durchaus präsent, doch nicht in der bedrohlichen Weise wie beim Nachbarn östlich des Rheins.

Die Erfahrungshorizonte Konservativer Revolutionäre in Deutschland und der Nonkonformisten wichen also in diesem Punkt deutlich voneinander ab. Auch im Erlebnis des Krieges zeigen sich erhebliche Differenzen. Ein Großteil der Konservativen Revolutionäre entstammte der Frontkämpfergeneration und stilisierte nachträglich den verlorenen Krieg zur Geburtsstunde des neuen Nationalismus. In Frankreich fehlte ein solcher Mythos vollständig. Aus einem einfachen Grund: Das Land war als Sieger daraus hervorgegangen, allerdings als ein geschwächter Sieger. Auf Frankreichs Boden waren die schwersten Schlachten geschlagen worden, und die Verluste hatten in dem Land besonders große Lücken hinterlassen. Nahezu einhellig äußerten alle Kreise in Politik und Gesellschaft die Auffassung, daß sich ein solcher Krieg niemals wiederholen dürfe, da er die Lebenskraft des französischen Volkes bedrohte. Diese Haltung klingt auch in sämtlichen Stellungnahmen der Nonkonformisten an. Eine mythische Überhöhung des Krieges als Sinnbild einer neuen Gemeinschaft war daher ausgeschlossen. Vielmehr artikulierten die Nonkonformisten eine vehemente Kritik an den Überlebenden der Frontkämpfergeneration. Die Toten wurden zu heroischen Opfern des Sieges über das feindliche Deutschland stilisiert. Den Überlebenden hingegen unterstellte man Feigheit und Schwäche. Sie wurden verantwortlich gemacht für Stagnation und Krise.

In dieser Aufarbeitung des Kriegserlebnisses unterscheiden sich Konservative Revolution und Nonkonformisten erheblich. Übereinstimmungen ergeben sich jedoch in der Stoßrichtung der Kritik: Auf beiden Seiten des Rheins richtete sich die Argumentation gegen die bestehende Ordnung. Und in beiden Staaten äußerte sich der Protest als Generationenkonflikt mit all seinen Implikationen von Jugend, Dynamik und antibürgerlichen Ressentiments. Immer stand dahinter der Wunsch nach Aufbruch, nach Veränderung und Überwindung der gesellschaftlichen und politischen Verhältnisse.

Stärker als in Deutschland fanden die Konservativen Revolutionäre in Frankreich ihren politischen Standort in den Auseinandersetzungen der Intellektuellen, die seit der Dreyfus-Affäre mit spezifischen Argumentationsmustern die öffentliche Diskussion bestimmten. Der Typus des Intellektuellen existierte ebenfalls in Deutschland. Gerade für die Weimarer Republik sind die Vielfalt der geistigen Strömungen und die lebhaften Konfrontationen charakteristisch. Auch die Art der Intervention, individuell oder kollektiv in politischen Fragen mit moralischen Argumenten einzugreifen, unterschied sich nicht von der in Frankreich geläufigen Praxis. Es fehlte jedoch eine vergleichbare integrative Kraft des Begriffes Intellektueller, wie sie für einen politischen Kampfbegriff notwendig ist. In Frankreich haben sich im Zuge der Dreyfus-Affäre Weltanschauungsund Wertesysteme herausgebildet, die in den Debatten seither präsent waren. Die Konfrontation zwischen dem Typus des liberalen Intellektuellen und des integralen Natio- 
nalisten bestimmte bis in die Zwischenkriegszeit hinein die Debatten. Benda und Péguy waren die beiden Pole, an denen sich die Auseinandersetzung innerhalb der Nonkonformisten entzündete. Gemeinsam war der Konservativen Revolution und den Nonkonformisten die Kombination von antiliberalem Denken und globaler Zivilisationskritik. Mit dieser Haltung schlugen sich die Gruppierungen auf die Seite der Gegner der Republik. Der Jugendmythos bot das geeignete rhetorische Instrumentarium, um die Gegner des republikanischen Systems zu mobilisieren. 